Portland State University

PDXScholar

1992

\title{
Adult student perceptions of traditionally sex-typed toys
}

Shelly Lynn Jackson

Portland State University

Follow this and additional works at: https://pdxscholar.library.pdx.edu/open_access_etds

Part of the Gender and Sexuality Commons, and the Psychology Commons Let us know how access to this document benefits you.

\section{Recommended Citation}

Jackson, Shelly Lynn, "Adult student perceptions of traditionally sex-typed toys" (1992). Dissertations and Theses. Paper 4327.

https://doi.org/10.15760/etd.6211

This Thesis is brought to you for free and open access. It has been accepted for inclusion in Dissertations and Theses by an authorized administrator of PDXScholar. Please contact us if we can make this document more accessible: pdxscholar@pdx.edu. 
AN ABSTRACT OF THE THESIS OF Shelly Lynn Jackson for the Master of Science in Psychology presented May 6, 1992.

Title: Adult Student Perceptions of Traditionally Sex-Typed Toys.

APPROVED BY THE MEMBERS OF THE THESIS COMMITTEE:
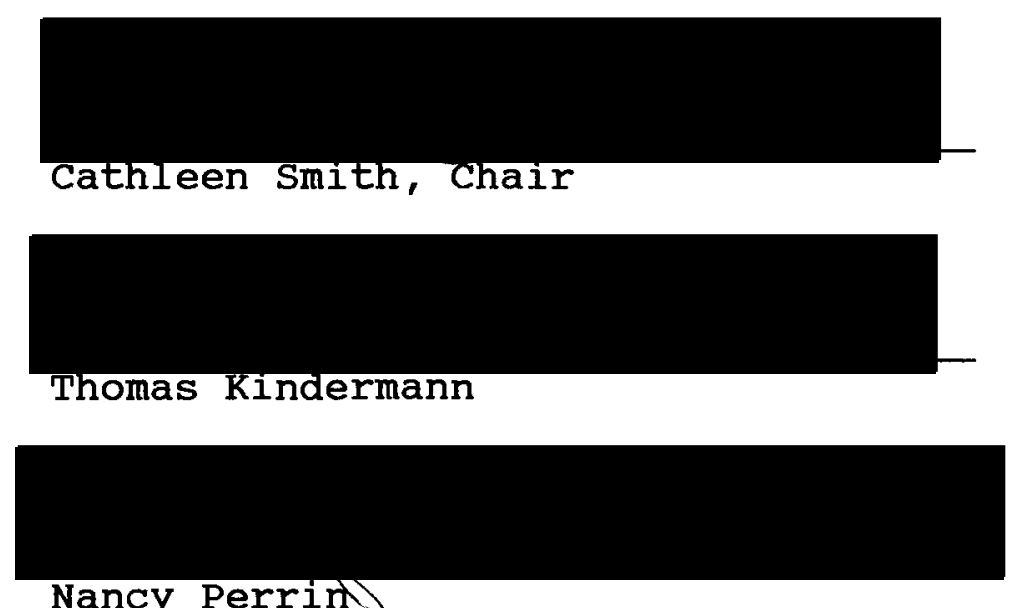

Nancy Perrins

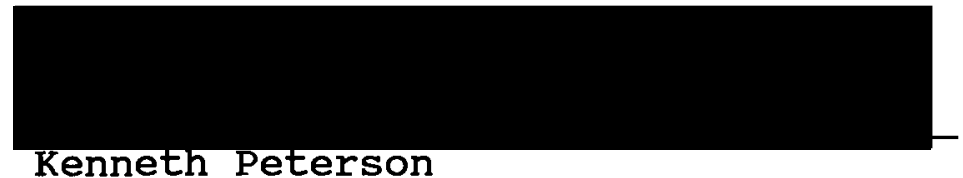

Studies have examined children's toy preferences as they relate to sex-role development. However, studies have failed to examine the dimensions of the toys themselves. Because adults purchase the majority of toys children receive, this study sought to determine adult student perceptions of children's traditionally sex-typed toys. 
Eighty-one participants rated ten selected toys. Multidimensional scaling analysis revealed five underlying dimensions. The five dimensions included Productive Play, Sociability, Structure, Gender, and Age. It was discovered that the Gender dimension was less salient than both the Productive Play and Sociability dimensions. The dimensions pertaining to each toy are discussed. 
ADULT STUDENT PERCEPTIONS OF TRADITIONALLY SEX-TYPED TOYS

by

SHELLY LYNN JACKSON

A thesis submitted in partial fulfillment of the requirements for the degree of

\section{MASTER OF SCIENCE \\ in \\ PSYCHOLOGY}

Portland State University

1992 
TO THE OFFICE OF GRADUATE STUDIES:

The members of the committee approve the thesis of Shelly Lynn Jackson presented May 6, 1992.

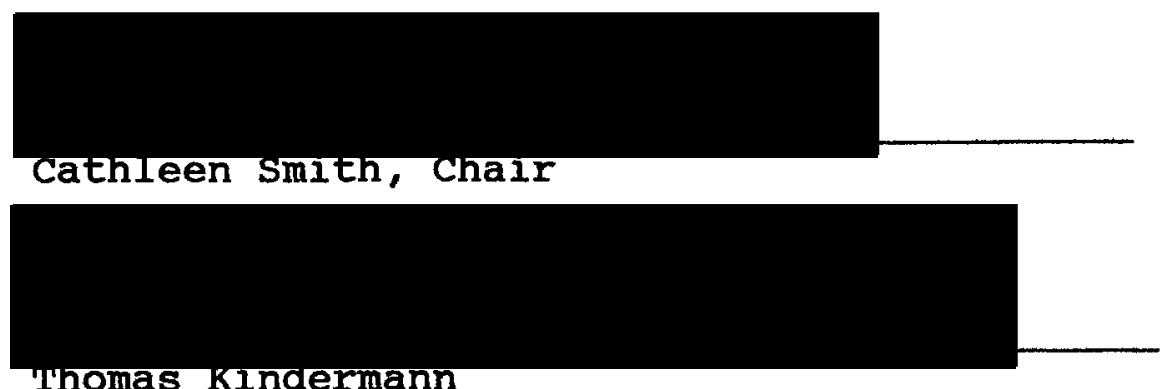

Thomas KIndermann

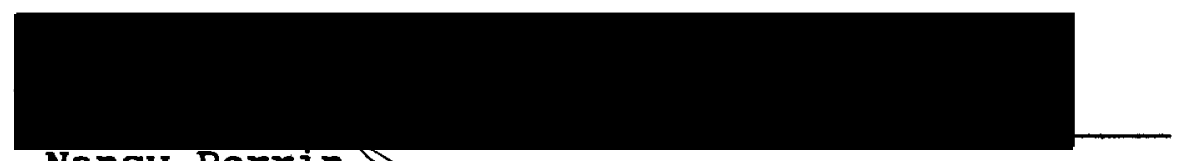

Nancy Perrin

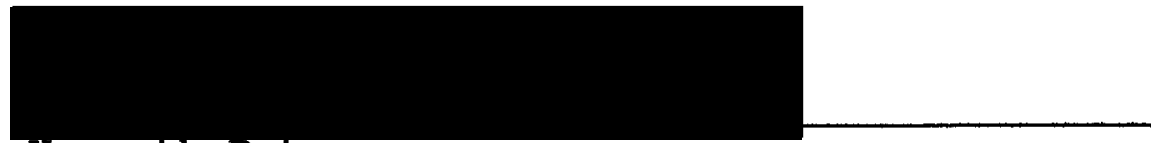

Kenneth Peterson

APPROVED :

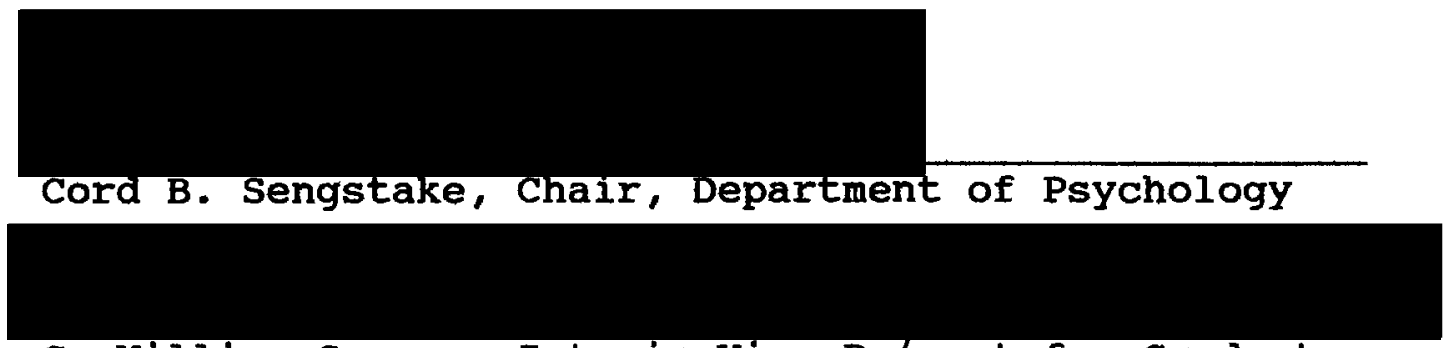

C. William Savery, Interim Vice Provost for Graduate Studies and Research 
TABLE OF CONTENTS

PAGE

LIST OF TABLES...................... v

LIST OF FIGURES..................... vi

INTRODUCTION. ........................ 1

Theoretical Background................. 1

Biological Differences Revisited............ 4

Cognitive Aspects of Gender Development........ 5

Differential Treatment of Boys and Girls....... 8

Influences on the Acquisition of Children's

Toy Preferences.................... 10

Multidimensionality of Sex Role Development...... 17

Consequences of Differential Toy Experiences..... 18

Purpose of the Present study.............. 20

Multidimensional scaling............... 21

Pilot study $\ldots \ldots \ldots \ldots \ldots \ldots \ldots \ldots \ldots \ldots \ldots \ldots \ldots$

METHODS.................................. 31

Subjects........................... 31

Stimuli (Toys) .................... 32

Tasks in the Questionnaire.............. 33

Procedure........................ 36

RESULTS........................... 41

Subject Removal..................... 41

Difference Scores.....................4 42 
MDS Analysis...................... 42

Correlations of INDSCAL Dimensions with Mean

Ratings on Eight Bipolar Scales......... 45

Examination of Weights................ 48

Verification of Research Toys................ 51

Bem Sex Role Inventory (BSRI) ............ 52

DISCUSSION.......................... 65

Toy Dimensions...................... 65

Implications: Toy Marketing, Intervention, and Future Research................ 78

REFERENCES CITED....................... 91 APPENDICES

A QUESTIONNAIRE.........................

B INFORMED CONSENT..................... 


\section{LIST OF TABLES}

TABLE

PAGE

I Sample Demographics............... 38

II Neutral, Masculine-, and Feminine-Sex-Typed Toys Reported in Toy Preference Research 39

III Demographics for the Removed Subjects....... 53

IV Stimulus Coordinates on MDS Dimensions...... 54

$\mathrm{V}$ Mean Ratings of Ten Toys on Eight Bipolar Scales.......................... 55

VI Correlation of INDSCAL Dimensions with Mean Ratings of Toys on Eight Bipolar Scales 56

VII Mean Weight Ratios for Males vs Females, Parents vs Child Care Workers, and All... 57

VIII Frequencies of Toys Found in Adult Homes and Child Care settings............... 58 


\section{LIST OF FIGURES}

FIGURE

PAGE

1. STRESS by Dimension plot................60

2. Productive Play vs Sociability............61

3. Productive Play vs structure.............. 62

4. Productive Play vs Gender.................63

5. Productive Play vs Age.................. 64

6. Diagram of Toy Dimensions............... 90 


\section{INTRODUCTION}

When sex-typing was first investigated there was an underlying assumption that traditional sex typing was a desirable phenomenon. Gradually, this view has shifted, and in many ways, has mirrored changes in the nonscientific view of gender roles. For example, evolution of the Women's Movement had a tremendous influence on changes within the scientific community (Carter, 1987). Studies began to reveal that males and females were more alike psychologically than they were different, with the exception of aggression, mathematical skills, and visual-spatial skills (Maccoby and Jacklin, 1974; Maccoby, 1990). No longer is it assumed that adoption of the appropriate masculine or feminine role is the only, or even the most desirable, outcome of sex role socialization.

\section{THEORETICAL BACKGROUND}

Huston (1983) and Roopnarine and Mounts (1987) each discuss several theoretical perspectives that exist with respect to sex-role development. The following is a short synopsis of the current sex-role developmental theories. The psychoanalytic perspective posits that sex roles are the 
result of an identification with the same sex parent. The neo-freudian viewpoint (Chodorow, 1974, cited in Gilligan, 1982) asserts that for boys and men, separation and individuation are critically tied to gender identity because separation from the mother is essential for the development of masculinity. For girls and women, development of a feminine identity does not depend on the achievement of separation from the mother or on the progress of individuation; rather, femininity is defined through attachment to the mother.

Social learning and cognitive theories have become more prevalent in the last few decades. Social learning theorists (Mischel, 1970) contend that parents and significant other adults in a child's life shape gender-role behavior by rewarding or praising gender-appropriate behaviors while punishing or discouraging genderinappropriate behaviors. Cognitive social learning theorists (Bandura, 1977; Mischel, 1973) allege that when children experience reinforcements and punishments, they tend to formulate certain expectancies that direct how they will subsequently respond to their social environments. Cognitive developmentalists (Kohlberg, 1966), on the other hand, maintain that changes in sex-typed behavior generally correspond to cognitive changes in logical thought development. According to this view, an understanding of the child's conception of gender is the cornerstone of 
gender development.

Currently, there are two information processing theories. The basic unit of schematic processing models of stereotyping is the notion of a schema. A schema is a cognitive structure, a network of associations that organize and guide an individual's perception. Martin and Halverson (1981) have introduced self-schema theory in which stereotypes are assumed to function as schemas. This theory proposes that children have a tendency to group information on the basis of gender, as gender is a stable and easily discriminable natural dichotomy. Schema-consistent information is made salient, while schema-inconsistent information is ignored (Carter \& Levy, 1988; Martin \& Halverson, 1987). Thus, only information that is relevant to one's own sex is processed.

The second information processing theory is gender schema theory (Bem, 1981; Bem 1983) which argues that sex typing, the process by which a society transmits male and female into masculine and feminine, results from the fact that the self-concept itself becomes assimilated to the gender schema. It is argued that gender-based schematic processing derives, in part, from society's ubiquitous insistence on the functional importance of the gender dichotomy. Gender schemas are central to a child's organization of information regarding sex-typed stereotypes. However, there is variability in the importance of gender 
schemas among individuals. Sex-typed individuals tend to process information on the basis of the gender schema more than nonsex-typed individuals. While it has been argued that the two information processing theories are different, Bem (1982) contends that they are not in direct opposition to one another.

It is evident from this brief description that several theories exist and that each theory posits a distinct viewpoint. Current research, however, suggests that sexrole development evolves from a variety of influences (Carter, 1987; Fagot \& Leinbach, 1987; Hort, Leinbach, \& Fagot, 1991).

\section{BIOLOGICAL DIFFERENCES REVISITED}

Sex-role developmental research initially focused on the role of biological factors in the acquisition of sexroles (Lewis \& Weinraub, 1979). No one will dispute the existence of biological differences between girls and boys (Huston, 1983). However, it now appears that males and females are born more similar than different. For example, humans are born with relatively immature brains. Girls and boys are exposed to different experiences (e.g., sex-typed toys) that are consistent, pervasive, and continual from the moment of birth. The consequences of these different experiences are hypothesized to be antecedents to some later 
biological differences, (e.g., the dimorphic brain structures found in males and females) (Hood, Draper, Crockett, \& Peterson, 1987; Liss, 1983).

COGNITIVE ASPECTS OF GENDER DEVELOPMENT

Debates continue concerning the relative importance of biological versus environmental factors in sex-role development. However, both biological and environmental perspectives view children as passive organisms (Lewis \& Weinraub, 1979). Increasingly, the role of cognition in sex-role development is being investigated. More specifically, the role of schemas (e.g., stereotypes) in sex-role development is of particular interest to many researchers. In the past, distortions in schematic processing, such as sexual and racial discrimination, led researchers to conclude that stereotyping had problematic consequences. More recently, research is suggesting that stereotyping is a normative cognitive process that is well in place by three years of age (Haugh, Hoffman, and Cowan, 1980; Martin and Halverson, 1981). Schemas about people serve to stabilize the perception of the social environment by making it more predictable and manageable. However, the differential treatment children receive has consequences for the development of their schemas. As Fagot and Leinbach (1983) point out, we should be concerned with what 
influences sex-role schemas.

There are two current theories pertaining to the development of gender schemas. One theory posits that sex schemas develop through an interaction with others; that is, through a process by which the child defines the self and defines the relation of the self to others (i.e., in-groupout-group comparisons). Lewis and Weinraub (1979) suggest that children may first use a limited number of frequently occurring physical appearance characteristics to distinguish between the sexes. Parents, teachers, and peers in the child's environment may provide additional information about groups by labeling group members as girls or boys. And finally, the child's recognition of his or her own membership in one gender group or another may also provide information to the child. Thus, it is on the basis of gender differentiation, and on the principle of interpersonal attraction, that the infant moves towards conformity.

Other research supports the contention that gender schemas tend to bias information processing by introducing distortions in memory for schematic-inconsistent material (Carter \& Levy, 1988). Thus, schemas produce behavior conformity by limiting the acquisition and/or retention of in-depth information about performing sex-inappropriate behaviors (Carter and Levy, 1988; Martin and Halverson, 1987). Each of these approaches provides explanations as to 
why children acquire information about the other gender, subsequent to learning about their own gender.

Studies are revealing that gender knowledge acquisition is best examined within a developmental framework. While it appears that gender knowledge develops with age, research has demonstrated that gender knowledge is evident by 18 to 20 months (O'Brien \& Huston, 1985; Strangor \& Ruble, 1987). As mentioned, children seem to learn samesex roles earlier than cross-sex roles (Lewis \& Weinraub, 1979; Liben \& Signorella, 1987; Martin, Wood, \& Little, 1990; Schau, Kahn, Diepold, \& Cherry, 1980).

Sex-typing is evident in children as young as two years of age. Age and gender schematization are positively associated with children's same-sex toy preferences (Carter \& Levy, 1988; O'Brien \& Huston, 1985). Studies have shown that, although children vary considerably in the ages at which they are able to recognize each other as boys and girls, gender labels for boys and girls are seen as early as 24 months, and for adults even earlier. Furthermore, children who label earlier tend to be more sex-typed in their toy choices than later labelers (Fagot \& Leinbach, 1989; Leinbach, 1991; Leinbach \& Fagot, 1986). Martin, Eisenbud, and Rose (1992) have shown that children prefer toys that are labeled for their own sex and avoid toys that are labeled for the opposite sex. According to Martin and Halverson (1987), the mere labeling of objects and 
activities seems to make gender schemas salient. The salience of gender schemas, in turn, serves to regulate behavior.

Controversy has ensued as to whether sex-typing occurs before or after the attainment of gender constancy, the recognition that gender is an invariant property of an individual. Liben and Signorella (1987) contend that gender takes on a certain importance to the child on the attainment of gender constancy. However, other studies argue that gender identity, the self-awareness of being male or female, not gender constancy, forms the basis for children's understanding of gender-relevant information (Carter \& Levy, 1988). Gelman, Collman, and Maccoby (1986) suggest that gender constancy is a classification task, tapping propertyto-category inferences; a skill that develops subsequently to inferring properties from category membership (i.e., gender identity). However, McConaghy (1979) found that gender permanence did precede an understanding of the genital basis of gender. Nevertheless, gender constancy is generally not considered a prerequisite for sex-typed behavior.

DIFFERENTIAL TREATMENT OF BOYS AND GIRLS

Even before a child's birth, there are differences in parents' preferences for and attitudes toward sons and 
daughters. Our society, as well as many others, exhibits a strong preference for male children. At birth, the sex of the child is the first fact announced to parents (Hoffman, 1977). Research has consistently demonstrated that parents interact differently with infants based solely on the gender label of the child (Huston, 1983). Thus, it is not surprising to learn that boys and girls are treated differently, even before differences manifest.

Consequently, boys and girls experience different environments beginning at birth (Hoffman, 1977; Huston, 1983). Children are often brought home from the hospital to gender-appropriately colored rooms (i.e., pink or yellow for girls and blue for boys) (Pomerleau, Bolduc, Malcuit, \& Cossette, 1990). Rheingold and cook (1975) and O'Brien and Huston (1985) examined the contents of childrens' rooms and found that parents provided different furnishings and toys for their sons and daughters. Boys' rooms were more often decorated with animal motifs whereas girls' rooms were more often decorated with floral designs, lace, fringe, and ruffles. Both boys and girls had more sex-typed toys than cross sex-typed toys at home; however, boys were provided with a greater variety of toys than girls. Thus, evidence strongly suggests that parents create differential experiences for boys and girls by providing sex-typed toys and furnishings. 
INFLUENCES ON THE ACQUISITION OF CHILDREN'S TOY PREFERENCES

\section{Parental Socialization of Toy Preferences}

Children's toy preferences are influenced not only by children's ages but also by what parents actually purchase and give to their children (Almqvist, 1989). Parents select different toys for their children, based on gender, before children can express their own preferences. Studies reveal that adults buy more sex-typed than nonsex-typed toys for their young children, and this pattern is especially pronounced when male customers purchase toys for boys (Fisher-Thompson, 1990). Toys typically purchased for girls are characteristically the playthings of the mother role (e.g., dolls, dishes) while the boys are given toys that represent the world of work (e.g., trucks, tools). The type of toys given to a child may indicate what the parent considers appropriate behavior.

Coury and Wolfgang (1984) suggest that because toys have an influence on children, determining children's toy preferences provides insight into development. Studies have sought to determine the influences on children's toy preferences. Because the first experience infants have with gender is in interacting with their parents (Huston, 1983; Leinbach, 1991), it can be hypothesized that parental socialization forms the basis for children's toy preferences. In fact, research has shown that children's 
stereotypes tend to be similar to their parents' stereotypes (Perloff, 1977).

Children's toy preferences are established at a very young age and these sex-typed toy preferences become even stronger with development (Fagot \& Leinbach, 1983; Huston, 1983). Studies reveal that toy preferences can be observed in children as early as 18 months (O'Brien \& Huston, 1985). However, as Eisenberg, Murray, and Hite (1982) warn, it is questionable whether children's sex-typed preferences are the result of conscious attempts to act in accordance with sex-role stereotypes. The socialization process is very subtle. Adults have traditional ideas about what toy is appropriate for which gender, and it is likely that these ideas will directly or indirectly affect children's toy preferences. Studies suggest that the antecedents of these toy preferences can be traced, in large part, to parental modeling, parental approval or support of children's interest in sex-stereotyped objects and play, as well as disapproval and punishment for children's interest cross-sex stereotyped objects and play (Fagot \& Leinbach, 1983; Garvey, 1990; Goldberg \& Lewis, 1967; Huston, 1983; Leinbach, 1991). This parental behavior is even more pronounced for males than for females (Fein, Johnson, Kosson, Stork, Wasserman, 1975). Many parents do not overtly promote play with same-sex-typed toys or discourage play with cross-sex toys. Instead, parents show a subtle 
tendency to respond more positively to, and be more involved with, same-sex than cross-sex toys (Caldera, Huston, \& O'Brien, 1989; Fagot \& Leinbach, 1989). In a recent book written explicitly for new parents, stern (1990) eloquently describes this subtle process as follows:

Let's suppose a baby girl around this age [12 months] comes upon a new toy truck and gets enthusiastic about it. She will look to her mother to see whether her mother shares her own high enthusiasm for this terrific new toy. Suppose the mother, for whatever reason at this point in social history, wants her to play with "girl toys," but not "boy toys." The little girl will start to learn that her mother shares her enthusiasm only in respect to certain kinds of toys. When it comes to trucks and such, her mother, being modern women, would never say "No!" or anything so blatantly disapproving. The effect is more subtle than that. The girl will simply feel that her inner mental state of enthusiasm is not particularly desirable if the mother responds with faint enthusiasm, or even undesirable if the mother responds with a rebuke or not at all. The sharing or nonsharing of mental states is a powerful way to shape another person's behavior (pp. 86-87).

Parents expect their children to play with culturally defined sex-appropriate toys and studies show that children subsequently request and play with same-sex stereotyped toys rather than cross-sex stereotyped toys (Caldera, Huston, \& o'Brien, 1989; Carter \& Levy, 1988; Huston, 1983; Martin, Eisenbud, \& Rose, 1992). However, while children are very sex-typical in their behavior, they are not as sex-typed in their toy play behavior as many parents believe they are (Schau et al., 1980). Fagot (1981) has demonstrated that parents overestimate sex-typing in their children, whereas 
child care workers underestimate sex-typed behaviors in children. We can infer from these studies that parents exert a tremendous influence on the acquisition of childrens' toy preferences.

Although the family is the principle context in which human development takes place, it is but one of several settings in which the developmental process can and does occur (Bronfenbrenner, 1986). Thus, while parental behavior may be a precursor to children's toy preference, there are many other domains that exert considerable leverage. As the child's world expands, peers, teachers, and the media come to exert a greater influence on toy preferences.

\section{Peer Socialization of Toy Preferences}

Peers as socializers of childrens' toy preferences have been studied extensively. Results generally confirm that peers are potent socializers of gender-appropriate behavior (Carter, 1987; Eisenberg, Tryon, \& Cameron, 1984; La Freniere, Strayer, \& Gauthier, 1984; Lamb \& Roopnarine, 1979; Maccoby, 1990; Shell \& Eisenberg, 1990; Wynn \& Fletcher, 1987). Carter (1987) suggests that peers exhibit an influence on one another by several methods. First, children self-segregate into single-sex peer groups. Research has shown that girls begin to prefer same-sex peers earlier than boys, who subsequently surpass girls in sexual discrimination. In addition, older children tend to exhibit 
stronger preferences for same-sex social partners than younger children (Carter, 1987; La Freniere et al., 1984; Maccoby, 1990).

studies have also found a relation between whom children play with and the sex-typing of their toy choices. For example, boys who play with other boys are more likely to play with masculine-sex-typed toys than feminine-sextyped toys. However, toy choice is not as predictable when children are playing in cross-sex groups as when they are playing in same-sex groups (Carter, 1987; Eisenberg et al., 1984; Shell \& Eisenberg, 1990).

Another technique that peers use to influence each other is direct reinforcement and punishment of sex-typed and cross-sex-typed verbal and nonverbal behaviors. This behavior can be seen as early as three years of age. Studies have shown that children who play with sexinappropriate toys are generally left alone by their agemates (Carter, 1987; Wynn \& Fletcher, 1987). This can readily be seen as a form of punishment.

And finally, research suggests that children's conceptions about stereotypes, and their beliefs about the responses of peers to sex-typical and sex-atypical behavior, also serve to influence peer behavior. Once a stereotype or schema is in place, it serves to prompt the unflagging reinforcing and punishing behaviors observed in children (Carter, 1987). 
Teacher Socialization of Toy Preferences

Teachers also exhibit a differential style towards girls and boys. Differences in the level of teacher experience have been suggested as an antecedent to this behavior. Fagot (1978) has demonstrated that inexperienced teachers tend to go along with children's play preferences while experienced teachers direct children into activities they consider more important to academic success (i.e., feminine behaviors), regardless of the sex of the child. Feminine behaviors, at least for young children, appear to be conducive to academic success.

Gender bias in teachers is not intentional, but is a very subtle process. And when teachers are made aware of their behavior, they are willing and eager to change (AAUW, 1992). Studies have demonstrated the ability of teacher intervention to increase the amount of cross-sexed play through reinforcement, suggesting that cross-sex-typed play is under environmental control (Fagot \& Leinbach, 1983; Sprafkin, Serbin, Denier, \& Connor, 1983). However, Ross and Ross (1972) found that boys were more likely to resist sex-inappropriate behavior advocated by an esteemed female teacher. Nonetheless, these studies provide further evidence of the substantial influence teachers possess. And equally important, these results suggest that teachers have the power to alter stereotypes and behaviors that are already established by the time children enter school. 
Media Socialization of Toy Preferences

Studies support the contention that the media (e.g., books, movies, television, magazines) are yet another powerful influence on gender socialization and toy preferences (Balaban \& Cooper, 1981; Connor \& Serbin, 1978; Cordua, McGraw, \& Drabman, 1979; Flerx, Fidler, \& Rogers, 1976; Huston, Wright, Rice, Kerkman, \& St. Peters, 1990; McGhee \& Frueh, 1980). Studies indicate that early childhood is an important period for the acquisition of television viewing patterns and that such patterns have long-term implications for children's development (Huston et al., 1990). McGhee and Frueh (1980) suggest that heavy television viewing may significantly contribute to children's acquisition of stereotypical perceptions of behavior and psychological characteristics associated with males and females.

Both girls and boys are watching as much as 2 to 3.5 hours of television a day. However, they are portrayed on television in very different roles; men are typically portrayed in higher occupational roles than women. In addition, men outnumber women in television programming at least 3:1. (Kunkel \& Murray, 1991; Zebrowitz McArthur \& Eisen, 1976). Williams, Haertel, Haertel, and Walberg (1982) conducted a literature review and concluded that females were adversely affected academically by the discrepancies found on television. Because girls do not see 
themselves on television, they can only assume that they do not count.

Media intervention studies propose that stereotypical perceptions can be ameliorated with egalitarian media presentations. A study by Flerx et al. (1976) found that the presentation of egalitarian sex-role models in books and films reduced sex-role stereotyping. Ashton (1983) found that preschool children more often chose a sex-stereotypical toy following exposure to a sex-stereotypical children's book. Conversely, boys and girls exposed to a nonstereotypical book significantly more often selected a nonstereotypical toy. Thus, while books, television, and films are important factors in the development of stereotypical attitudes, they can also be influential in reversing established stereotypes.

\section{MULTIDIMENSIONALITY OF SEX ROLE DEVELOPMENT}

Researchers previously believed that masculinity and femininity were two polar opposites on the same continuum (Windle, 1987). It now appears that the content domain of sex-roles and sex-typing cannot be characterized as homogenous. Peretti and sydney (1984) assert that sextyping does not occur through toys alone but through a multitude of social, situational, and psychological factors. The child's own gender development, influenced by parent- 
peer-teacher-media-child interactions, is best characterized as a multidimensional construct (Fagot \& Leinbach, 1987; Hort et al., 1991). Any attempt to explain the acquisition of sex-typed behavior through one of these processes alone would be "doomed to disappointment" (Maccoby Jacklin, 1974). It is increasingly clear that the use of sophisticated, multidimensional approaches is necessary if we are to advance our understanding of the development and process of sex-typing (Carter, 1987). Connor and Serbin (1977) and Eisenberg (1983) warn that only when toy preferences are measured using observational methods can we be sure they represent the children's preferences and not mental adoption patterns, based in part on environmental pressures. Thus, it is necessary to measure behaviors and preferences through observation and analyze the data using multidimensional techniques.

\section{CONSEQUENCES OF DIFFERENTIAL TOY EXPERIENCES}

As we have seen, parents, peers, teachers, and the media serve to create different experiences for boys and girls. As a consequence of playing with different toys, boys and girls develop different specific skills, abilities, and behaviors. Repetitive play with toys stereotypically considered to be masculine, and preferred by boys, provides a greater opportunity to manipulate the environment three- 
dimensionally. This is believed to foster visual-spatial ability even before sex differences in visual-spatial problem solving appear (Serbin \& Connor, 1979; Sprafkin et al., 1983). Hoffman (1977) has suggested that boy's experiences, which girls lack, very likely have considerable importance in the development of independent coping styles, a sense of competence, and even specific skills. The sextype of a toy that a child plays with has been found to be a better predictor of that child's skills or actions than the child's gender (Liss, 1983).

The consequences of children's disparate experiences with toys can have profound effects on academic achievement and career aspirations (Serbin, Zelkowitz, Doyle, Gold, \& Wheaton, 1990). Several studies exist to confirm this assertion. Fagot and Littman (1976) found that girls whose play interests had been masculine in preschool were rated higher in all areas of achievement (e.g., science, mathematics, and language arts) compared to those with feminine play interests. In another study, Metzler-Brennan, Lewis, and Gerrard (1985) concluded that the childhood experiences of women who later chose a career were distinct from the childhood experiences of women who chose to be homemakers. Career oriented women reported more play with masculine-sex-typed toys than homemakers. In yet another study, it was again suggested that boys and girls learn different skills by participating in activities differing in 
structure. The abilities to "create structure" (e.g., masculine-sex-typed toys) and to "fit into structures created by others" (e.g., feminine-sex-typed toys) were suggested as antecedents of the well-documented discrepancy between males and females in all recognized fields and levels of achievement (Carpenter Huston-Stein, 1980).

\section{PURPOSE OF THE PRESENT STUDY}

As we have seen, adults interact and purchase toys differentially for their children based primarily on the child's gender. A myriad of studies have been conducted to determine which toys are preferred by children and which toys adults consider masculine and feminine. However, research has failed to discover specifically what dimensions are involved in various sex-typed toys. It is likely that adults use cues other than gender to classify a toy. The purpose of this study is to determine the underlying dimensions of traditionally sex-typed toys through the use of adult perceptions. A second goal is to combine dimensions that have been used separately in several existing studies in one comprehensive assessment. These goals will be accomplished by use of multidimensional scaling. Thus, in an effort to acquaint the reader with this type of analysis, I will first present a brief overview of multidimensional scaling. 
MULTIDIMENSIONAL SCALING

Multidimensional scaling (MDS) is a data analytic procedure that enables a researcher to reduce the data to a certain number of dimensions representing the "hidden structure" of a group of stimuli. In that MDS is used to describe structure, it is similar to factor analysis, but MDS can examine both metric and nonmetric data. It has the seemingly paradoxical ability to extract quantitative, metric information from qualitative, nonmetric data. MDS has proven useful to researchers in many fields including anthropology, political science, education, marketing, and psychology.

The MDS models use a square, symmetric proximity (dissimilarity) matrix as input, in which each cell of an $n \times n$ matrix contains some measure of the dissimilarity. Some MDS models use a series of $n \times n$ matrices of dissimilarity, one for each subject. A proximity is a number defined over pairs of stimuli, which indicates how different (or similar) two stimuli are, or are perceived to be. If the proximity measures are scored so that the highest values correspond to stimulus pairs that are least alike, then it is a measure of dissimilarity. Common types of proximities include similarity, dissimilarity, correlation, and confusion matrices.

other methods for obtaining proximities data include 
having subjects sort, or cluster, the stimuli according to the perceived dissimilarity. Also, several types of stimulus confusability methods can be used as a measure of proximity. Additionally, the amount of communication and interaction between individuals or groups can be considered proximity measures.

In order to discover, rather than impose the dimensions, the attributes on which the subjects are to judge the stimuli are not specified. However, subjects can be asked about specific kinds of dissimilarity. Most MDS studies employ direct dissimilarity judgments as measures of dissimilarity. Subjects rate all possible pairs of objects on a dissimilarity scale, generally from 1 to 9 . Subsequent to the dissimilarity ratings, subjects commonly rate stimuli on a set of bipolar scales (also generally on a scale from 1 to 9) chosen to give information about possible dimensions the subjects use when making the dissimilarity judgments. It is suggested that researchers should use less than 12 stimuli because the number of paired comparisons can get quite large.

There are three models of MDS. While I will be using the Weighted Euclidean MDS model, I will briefly discuss the other two. All three models are based on dissimilarities measured between objects in which $d$ represents the measured dissimilarity between objects $A$ and $B$. The larger $d$, the more dissimilar the objects are. These dissimilarities are 
scaled into distances by MDS. The distances are assumed to exist in a multidimensional psychological space, where the dimensions represent attributes of the objects. According to the Simple Euclidean model, the distance measures are related to the attribute levels by the following function:

$$
d_{(A, B)}=\left[\Sigma\left(x_{k A}-x_{k B}\right)^{2}\right]^{1 / 2}
$$

where $d_{(\lambda, B)}$ refers to the distance between $A$ and $B$, and $x_{k A}$ and $x_{k B}$ refer to coordinate estimates of the two stimuli on dimension $k$. If the objects are cars, for example a Honda and a Jaguar, and one attribute is gas mileage, then $x_{k a}$ and $X_{k B}$ would be the coordinates in the space that represents the gas mileage of two cars. These values are theoretical quantities which cannot be observed but must be estimated from the data. In the simple Euclidean model, all subjects are assumed to have the same psychological space and the dimensions are assumed to be orthogonal.

The chief output in Simple Euclidean MDS is a stimulus coordinate matrix, in which the coordinates are like factor loadings. Each row corresponds to a stimulus and each column corresponds to one of the dimensions. Thus, in the coordinate matrix $x, x_{\mathbf{A k}}$ is the coordinate for stimulus object $A$ on dimension $\mathrm{k}$. The coordinate matrix can contain as many columns as is needed to describe all the stimulus dimensions.

The stimulus coordinate matrix has a geometric interpretation that makes it possible to display an abstract 
coordinate matrix as a graph. This results in a spatial representation (i.e., stimulus map), consisting of a geometric configuration of points, as on a map. When presented graphically, stimuli are represented as points and each is labeled to indicate which object it represents. Attributes, or dimensions, are presented as axes. Solutions of more than two dimensions are presented as a series of two-dimensional plots, with one plot in the series for each pair of dimensions. As previously mentioned, the configuration reflects the "hidden structure" in the data. There is no parameter for individual differences in the Simple Euclidean MDS model.

The second MDS model is the Weighted Euclidean MDS model, which allows for individual differences in the psychological space. This model assumes that different individuals perceive the stimuli in terms of a common set of dimensions, but that these dimensions are differentially important or salient in the perception of different individuals. The formula relating distances for a particular subject to the stimulus coordinates and dimension weights is given by:

$$
d(A, B)=\left[\sum w_{k S}^{2}\left(x_{k A}-x_{k B B}\right)^{2}\right]^{1 / 2}
$$

where $w_{k 1}$ is the weight of subject $i$ on dimension $k$. This formula differs from the simple Euclidean distance formula only in the presence of weights, which represent salience or importance, thereby allowing the dimensions to be unequal. 
Each subject will have a weight for each dimension. Output will still produce a group stimulus matrix, but it will also produce an estimate of a matrix of subjects' weights. The resulting dimensions will be orthogonal. If the weights are equal the Weighted model reduces to the Simple model.

The stimulus coordinate matrix is multiplied by each subject's diagonal weight matrix. These weights stretch and shrink the initial map into a personal psychological map. Thus, each persons' stimulus map will look different. All other things equal, as the weight increases, differences between stimuli along that dimension have a larger and larger influence on the judged dissimilarity between stimuli $A$ and $B$.

The weighted model allows the weights to be different for every person and, therefore, allows us to talk about individual differences. The square of a subject's weight on a particular dimension indicates the proportion of variance in his dissimilarities data which can be accounted for by that dimension. The sum of the squared weights across all dimensions for each person will provide the percentage of total variance accounted for by the dimensions for each person, thereby providing a detailed account of how well the model predicts the data for each person.

The final MDS model is the General Euclidean MDS model. While the previous two models will always result in an orthogonal solution, the General model allows the dimensions 
to be correlated. Correlations between the dimensions may occur because of perceptual dependencies between attributes. This model is represented by the function:

$$
d(A, B)=\left[w_{x 1}{ }^{2}\left(x_{A}-x_{B}\right)^{2}+w_{y 1}{ }^{2}\left(y_{A}-y_{B}\right)^{2}-2 w_{X 1} w_{y 1} \cos \theta_{1}\left(x_{A}-x_{B}\right)\left(y_{A}-y_{B}\right)\right]^{1 / 2}
$$

in which there is a weight for each dimension and a theta, $\theta$, for each pair of dimensions. Theta is the angle between $A$ and B. If $\theta=90^{\circ}$, then $\cos \theta=0$ and the dimensions are said to be independent. In this case, the General model reduces to the Weighted Euclidean model. If $\cos \theta$ is anything other than 0 , the dimensions are said to be dependent.

MDS provides two overall goodness of fit indices. The first one is STRESS which is an indication of how well the configuration represents the data across persons. STRESS is the square root of a normalized "residual sum of squares" of the predicted and observed matrices, and is analogous to the standard error of estimate in regression. Lower STRESS values indicate better fit (i.e., close to zero). The other overall goodness of fit measure is RQS which also provides an indication as to whether the dimensions represent all the structure in the proximity matrix. Like $R^{2}$ a value close to one indicates a good RQS fit.

Typically solutions are obtained in several dimensionalities and the researcher must choose among them. In determining how many dimensions to retain, one looks at interpretability, ease of use, stability, and STRESS. There 
are two approaches to the use of STRESS as a guide to dimensionality. The first plots STREss as a function of dimensionality. The plot is interpreted by the visual sharpness of the bend in the plot. The point at which the plot begins to level off indicates the number of dimensions to retain. The other approach involves intuition and experience. The decision to stop adding dimensions is made when additional dimensions do not provide any additional insight into the data and do not add significantly to the variance accounted for.

Interpretation of the dimensions consists largely of identifying important stimulus groupings or orderings. As we move farther and farther in some particular direction on the spatial representational space, the points that we successively encounter correspond to objects that possess more and more of some particular, identifiable property. We can then conclude that this property, unlike properties that do not have any discernible relation to the spatial representation, played an important role in whatever process gave rise to the data.

When examining the coordinate matrix and the stimulus map there are several indicators to watch for. The larger the dissimilarity between two objects, as shown by their proximity value, the further apart they will be in the spatial map. Thus, the researcher will look at these coordinate values and the stimulus map for apparent 
arrangements of data points and seek labels for the resulting dimensions. Additionally, the researcher must describe the features shared in common by each stimulus grouping.

Another technique to aid in interpretation is to use the neighborhood interpretation which focuses on what the smallest distances might have in common. If alternative interpretations are plausible, they should be reported.

While not directly part of MDS, it is useful to select some dimensions and ask subjects to make bipolar ratings on each stimulus on each of the dimensions. These ratings are used to help interpret the dimensions from the MDS solution. Correlations, or multiple regression, are commonly used to test if positions in the configuration are systematically associated with some of the rated characteristics. In addition to aiding in choosing the appropriate dimensionality, correlation or multiple regression is often used to indicate which particular characteristics are important in contrast to others which might be just as plausible.

To calculate a correlation for each bipolar scale, the means for each stimulus on the bipolar ratings and the stimulus coordinates of each dimension are used. Thus, a table with correlations of each dimension with each bipolar scale results. Ideally, each bipolar scale should demonstrate only one high correlation with the bipolar 
scales. Through the use of correlations or multiple regression, a very simple, statistically supported description can be given of the major patterns in the data.

\section{PILOT STUDY}

A nine page questionnaire containing several tasks was designed to gather relevant information from participants. Participants would first provide the following demographic information: Whether they were a parent or a child care worker, their age, sex, educational level, and number, age, and sex of each of their children (if any). Subsequently, participants would rate all possible pairs of ten toys on a dissimilarity scale from 1 to 9. Following this, participants would rate each of the ten toys on eight dimensions, 80 ratings in total, along a 9 point scale. Next, participants would report which toys that were used in the study were also in their homes (if any). And finally, participants would complete a 60 item self-Descriptive Inventory. (Each of these tasks are delineated at length in a subsequent section. Also, see Appendix A). Completion of the questionnaire would constitute a session.

Subsequent to designing the questionnaire, a small pilot study $(N=9)$ was conducted to ascertain the length of each session (to be able to provide this information upon recruitment and to ensure the participants would not be 
exhausted upon completion of the questionnaire). It was also necessary to determine whether there were any unforseen problems with the questionnaire. Seven female parents (with a mean age of 36 ) and two male parents (with a mean age of 30) served as subjects. Each participant had between 1 and 3 children. All nine participants were between their sophomore and senior year at a local metropolitan university.

From the results of this pilot study, it was discovered that three difficulties existed with respect to the questionnaire. These difficulties were promptly resolved by amending the instructions in the questionnaire, and thereby clarifying what we were looking for. First, we included the phrase "Using any criteria you choose,..." to the ratings instructions. Second, we included the phrase "In all the ratings below, please give your opinion, not what other people think." And finally, the instructions used in determining whether people had the research toys in their homes or not were completely changed, but the essential change was to include the phrase "... whether you have in your home, or have had in your home at one time...." Furthermore, the estimated session length of 20 to 35 minutes was verified, with most subjects completing the questionnaire in approximately 25 minutes. The data collected from the pilot study were not used in the actual study. 
METHODS

SUBJECTS

For this study, 81 parents and/or child care workers participated. Parents and child care workers were recruited on a voluntary basis from undergraduate and graduate level psychology classes at a metropolitan university and from the university's student Parent Services department. Participants' ages ranged from 18 to 51 , with a mean age of 33. All participants were enrolled in the university. Seven participants were freshmen, eight were sophomores, 18 were juniors, 32 were seniors, and 13 were graduate students. Three subjects did not indicate education level. Female parents had an average of 2.15 children, and male parents had an average of 2.05 children. If child care workers had children, they were classified as parents. Consequently, none of the child care workers had children. The average age of the participants' children was elevenand-a-half years of age. The sex of each of their children at each ordinal position was evenly distributed, except for the third child, in which there were almost three times as many boys as girls. Table I summarizes the demographics for this sample. 
STIMULI (TOYS)

Toys were selected on the basis of previous toy preference research. An examination of studies purporting to use "masculine-" or "feminine-sex-typed" toys was conducted. A broad list of toys was assembled, and then while engaged in the literature review, a tally mark was placed beside each toy that was mentioned in the literature (see Table II for a list of references pertaining to each toy). Toys that were most frequently used in toy preference literature were selected for this study, except for the jump rope. The jump rope was the only reported sports-like activity specifically for girls, and therefore was chosen as a feminine-sex-typed sports activity to match the masculinesex-typed sports activity of baseball. Once the type of toys was determined, an examination of the toys in Toys $R$ Us, KB Toys, K-Mart, Imaginarium, City Kids, and Child's play retail stores revealed that some of the toys came in various colors. For example, wooden blocks could be purchased that were either brightly colored or natural in color. Since there were far more brightly colored blocks than neutral blocks available, the brightly colored blocks were purchased. Thus, toys that were available in more than one color were selected on the basis of frequency in the toy store.

Based on the above criteria, a total of ten stimuli 
(i.e., toys) were selected. Four masculine- and four feminine-sex-typed toys, and two neutral toys were chosen. Masculine-sex-typed toys included an Easton IncrediBall baseball, NSI Colored Wooden Blocks, Shelcore Little Fix-It Tool Box (i.e., carpenter set), and a Tonka Quarry Dump Truck. The feminine-sex-typed toys included a Barval La Baby doll, a Geoffrey jump rope, Betty's Quickpoint (i.e., sewing kit), and a Prang Portable Painting Kit. The two neutral toys selected were Kenner Play-Doh and a wooden United states map puzzle.

\section{TASKS IN THE QUESTIONNAIRE}

\section{Demographic Information}

Each subject completed a short demographic questionnaire requesting the following information: Whether the subject was a parent or a child care worker, the subjects' age, sex, education, as well as number, age, and sex of each of their children (if any). See Appendix $A$ for a sample of the complete questionnaire.

\section{Dissimilarity Ratings}

Subjects were instructed to make judgments of the overall dissimilarity between all possible pairs of toys, 45 pairs in total, along a 9 point rating scale ranging from "Highly Similar" to "Highly Dissimilar". The stimulus pairs 
were presented in the same order for each subject. In an effort to reduce presentation bias in paired comparison procedures, a Ross-1ike ordering pattern was used (i.e., alternating the presentation of stimuli) (Davidson, 1983). Subjects were encouraged to use whatever criteria they desired in making their judgments. Before making the judgments subjects were instructed to look over the display of toys and to take their time. They were also told that they were free to ask questions at any time. subjects were seated about six to eight feet from the actual toys and had access to the toys if desired.

In an effort to justify the ordering of the pairs of stimuli (see Difference Scores, p. 42), the third, sixth, and ninth stimulus pairs from the first page were repeated on the bottom of the second page.

\section{Semantic Differential Ratings}

Semantic differential ratings or bipolar scales are used to aid in interpretation of the dimensions and to support dimension interpretation. Baird \& Noma (1978) suggest that it is best to have some a priori theory of the dimensions before applying this technique. Dimensions were chosen following a careful examination of existing literature describing the various ways in which toys aid in the development of affective and cognitive skills. From this review, eight dimensions were selected accordingly: 
Texture (soft vs rough) (Leinbach \& Hort; 1989); Color (pale vs bright) (Fisher-Thompson, 1990; Leinbach \& Hort, 1989); Shape (rounded curves vs sharp lines) (Leinbach \& Hort, 1989); Activity (fine motor movement vs gross motor movement) (Eaton, Bargo, \& Keats, 1981; Goldberg \& Lewis, 1967; Hoffman, 1977; Huston, 1983; Liss, 1983; Tracy, 1990); Sociability (small group activity vs large group activity) (Huston, 1983; Maccoby, 1990); Gender (feminine vs masculine); Depth (two-dimensional vs three-dimensional) (Serbin \& Connor, 1979; Tracy, 1990); and Structure (high structure vs low structure) (Carpenter \& Huston-Stein, 1980; Wolfgang, 1983). Subsequent to completing the dissimilarity ratings, subjects rated each of the ten toys on each of the eight dimensions, 80 ratings in total, along a 9 point scale. The anchors for each of the ten dimensions are provided in the above paragraph. The stimuli within each of the dimension ratings were presented in random order, although all subjects were exposed to identical questionnaires.

\section{Additional Question}

An attempt was made to determine how familiar participants were with the research toys, and thereby insure that the toys we selected were relevant to the participants. Therefore, following the dimension ratings, participants were asked concerning each toy "Do you have or have you ever 
had Exactly This Toy, A Similar Toy But Different Version, or You Do Not Have This Toy In Your Home?"

\section{Bem Sex Rele Inventory (BSRI)}

To ascertain the traditionality of the sample, participants were required to complete a 60 item SelfDescriptive Inventory, officially known as the Bem Sex Role Inventory (Bem, 1974). This Inventory contained 60 adjectives that were to be rated on a scale from 1 to 7 , with 7 being extremely descriptive of Self.

\section{PROCEDURE}

Participants congregated at a designated room in the psychology department at specified (i.e., sign-up) times, with no more than 10 participants at a time. A long, narrow table against a wall displayed the ten toys. Participants were seated at a large conference-style table in the middle of the room with chairs arranged along one side of the table so that participants were directly facing the toy display. Once the participants were seated, the experimenter thanked them for coming and gave a few brief instructions concerning the consent form (see Appendix B). Upon completion of the signed consent form, participants returned the consent form to the experimenter and, in return, received the questionnaire. Participants were 
instructed that they could ask any questions throughout the procedure, and that they were free to initiate contact with the toys at any time. Participants then proceeded to fill out the questionnaire in the same order that the forms were described above.

Upon completion of the five sections, participants handed in the questionnaire to the experimenter. They were each thanked for participating and asked if they had any questions regarding the questionnaire. Departure of all participants from the room constituted one session of testing. This process was repeated upon arrival of the next group of participants. Each person was given one hour to complete the forms, although the average time of completion was 25 minutes. Data collection occurred during the first two weeks in January, 1992. 
TABLE I

SAMPLE DEMOGRAPHICS

$\begin{array}{cccc}\text { MALE } & \text { FEMALE } & \text { MALE } & \text { FEMALE } \\ \text { PARENT } & \text { PARENT } & \text { CCW } & \text { CCW }\end{array}$

$\mathbf{N}$ 20

39

3

19

AGE (Mean)

39

34

27

24

YEAR IN SCHOOL (Freq)

$\begin{array}{lcccc}\text { Freshman } & 2 & 1 & - & 4 \\ \text { Sophomore } & - & 6 & 1 & 1 \\ \text { Junior } & 1 & 11 & 1 & 5 \\ \text { Senior } & 10 & 14 & 1 & 7 \\ \text { Graduate } & 5 & 6 & - & 2 \\ \text { ILDREN (Mean) } & 2.05 & 2.15 & - & - \\ \text { OF CHILDREN (Mean) } 8.75 & 11.25 & - & - \\ \text { OF CHILDREN (Freq) } & 18 & & & - \\ \text { Male } & 16 & 36 & - & - \\ \text { Female } & & & \end{array}$

Note: Two male parents and one female parent did not indicate education level. 
TABLE II

NEUTRAL, MASCULINE-, AND FEMININE-SEX-TYPED TOYS REPORTED IN TOY PREFERENCE RESEARCH

Sex-Typed Toy

Truck

Baseball

Carpenter set

Blocks
Studies in which each Toy is cited

Ashton, 1983; Caldera et al., 1989; Carpenter \& Huston-Stein, 1980; Connor \& Serbin, 1977; Eisenberg et al., 1982; Fagot, Leinbach, \& Hagan, 1986; Fein et al., 1975; Karpoe \& Olney, 1983; Lamb \& Roopnarine, 1979; Leinbach \& Hort, 1989; Maccoby \& Jacklin, 1974; Martin et al., 1990; Miller, 1987; O'Brien \& Huston, 1985; Pomerleau et al., 1990; Weinraub, Clemens, Sockloff, Ethridge, Gracely, \& Myers, 1984

Coury \& Wolfgang, 1984; Edelbrock \& Sugawara, 1978; Lamb \& Roopnarine, 1979; Leinbach \& Hort, 1989; Martin, 1989; Martin et al., 1990; Pomerleau et al., 1990; Rheingold \& Cook, 1975

Carpenter \& Huston-Stein, 1980; Coury \& Wolfgang, 1984; Edelbrock \& Sugawara, 1978; Eisenberg et al., 1982; Fagot et al., 1986; Fein et al., 1975; FisherThompson, 1990; Maccoby \& Jacklin, 1974; Martin et al., 1990; Miller, 1987; O'Brien \& Huston, 1985; Pomerleau et al., 1990; Schau et al., 1980; Weinraub et al., 1984

Caldera et al., 1989; Carpenter \& Huston-Stein, 1980; Connor \& Serbin, 1977; Eisenberg et al., 1982; Eisenberg et al., 1984; Fagot et al., 1986; Fisher-Thompson, 1990; Lamb \& Roopnarine, 1979; Leinbach \& Hort, 1989; Maccoby \& Jacklin, 1974; Miller, 1987 


\section{NEUTRAL, MASCULINE-, AND FEMININE-SEX-TYPED TOYS REPORTED IN TOY PREFERENCE RESEARCH (continued)}

Doll

Jump Rope

sewing kit

Painting set

Play-Doh

Puzzle
Ashton, 1983; Caldera et al., 1989; Carpenter \& Huston-Stein, 1980; Connor \& Serbin, 1977; Coury \& Wolfgang, 1984; Eisenberg et al., 1982; Eisenberg et al., 1984; Fagot et al., 1986; Fein et al., 1975; Fisher-Thompson, 1990; Karpoe \& Olney, 1983; Lamb \& Roopnarine, 1979; Maccoby \& Jacklin, 1974; Martin et a1., 1990; Miller, 1987; O'Brien \& Huston, 1985; Pomerleau et al., 1990; Rheingold \& Cook, 1975; Weinraub et al., 1984

Coury \& Wolfgang, 1984; Miller, 1987

Connor \& Serbin, 1977; Edelbrock \& Sugawara, 1978; Fisher-Thompson, 1990; Leinbach \& Hort, 1989; Maccoby \& Jacklin, 1974; Martin et al., 1990

Carpenter \& Huston-Stein, 1980; Connor \& Serbin, 1977; Eisenberg et al., 1984; Lamb \& Roopnarine, 1979; Maccoby \& Jacklin, 1974; Rheingold \& Cook, 1975

Carpenter \& Huston-Stein, 1980; Connor \& Serbin, 1977; Eisenberg et al., 1982; Maccoby \& Jacklin, 1974; Miller, 1987

Caldera et al., 1989; Carpenter \& Huston-Stein, 1980; Connor \& Serbin, 1977; Coury \& Wolfgang, 1984; Eisenberg et al., 1982; Eisenberg et al., 1984; Fisher-Thompson, 1990; Maccoby \& Jacklin, 1974 
RESULTS

SUBJECT REMOVAL

one-hundred and twenty subjects completed the questionnaire. However, 39 subjects were removed for the following reasons: (1) Five subjects had incomplete data. (2) Five subjects used ratings between 5 and 7 or 7 and 9 only. It was concluded that these participants failed to exhibit variability. (3) Twenty-nine subjects had extremely low RSQ's (i.e., RSQ's lower than .300). In this case, it was believed that these subjects may not be using any criteria consistently or were not using the same criteria as the rest of the sample. Therefore, their data would not fit the model.

In an attempt to explain the 27 low RSQ's, an examination of the demographic data and a separate MDS analysis was conducted. However, this examination failed to provide any conclusive evidence regarding differences in the demographics for this group. Their demographics are presented in Table III. In addition, an examination of the Weighted MDS model revealed that these subjects still had consistently low RSQ's, thus supporting the decision to remove them. 


\section{DIFFERENCE SCORES}

The order of the paired comparisons was determined by use of a Ross-like ordering system in which stimuli are presented in an alternating order throughout the list of paired comparisons (Davidson, 1983). However, while the stimuli were presented in an alternating sequence, all subjects were exposed to the same list of stimulus pairs.

In an effort to verify that subjects used the scale consistently, and to justify the ordering of the dissimilarities, three paired comparisons from the first page were repeated at the bottom of the second page of the dissimilarities section. For each pair a difference score was computed. Then a test of the hypothesis that the median difference score is zero was conducted for each of the three pairs. This procedure revealed that there was not a significant difference between the ratings on the first page and the ratings on the second page in all three pairs ( $D$ ) $.69 ; \mathrm{p}>.46 ; \mathrm{Q}>.27$ ).

\section{MDS ANALYSIS}

The dissimilarity ratings between every pair of stimuli for a particular subject were summarized. The set of 81 complete dissimilarity matrices, one for each subject, served as input to the MDs procedure. 
Because it was suspected that subjects may not use the dimensions independently, the General Euclidean model which allows for oblique dimensions was initially run. However, upon examination of correlations between dimensions found by the General Euclidean model, it was determined that there was no evidence to suggest that the dimensions were oblique.

Therefore, the Weighted Euclidean model, or the INDSCAL model, was employed. This model results in an orthogonal solution and allows us to talk about individual differences between subjects, or groups of subjects.

In judging how many dimensions should be retained, several solutions varying in the number of dimensions were obtained and a STRESS by dimensions plot was constructed (see Figure 1). By examining this plot (i.e., looking for a bend in the plot), as well as the RSQ values for each dimension (which should increase with increasing dimensions), it was determined that five dimensions were sufficient to account for the data. As further evidence that five dimensions should be kept, it was observed that the RSQ value decreased with inclusion of the 6th dimension. The overall STRESS value for five dimensions was .135 and the overall RSQ value was .571. The lowest individual RSQ was .203 and the highest individual RSQ was .938. It was determined that an additional dimension did not aid in the interpretability of the data. 
Interpretation of Dimensions

The stimulus coordinates from the five-dimensional

INDSCAL analysis are presented in Table IV. Figures $2-5$ display a plot of each of the dimensions with dimension 1 . The interpretation of Productive Play was given to the first dimension based upon the fact that those stimuli that yield a product are aligned on the left-hand side (painting set, carpenter set, sewing kit, puzzle, play-doh, and blocks) whereas the nonproductive toys are aligned on the right-hand side (jump rope, baseball, truck, and doll).

Dimension 2 was termed Sociability due to the fact that stimuli that can be played with in small groups are aligned at the bottom half of the graph (doll, truck, blocks, playdoh, puzzle, sewing kit, carpenter set, and painting set), whereas those toys that are typically played in larger groups are aligned at the top of the graph (baseball and jump rope).

Dimension 3 was interpreted as a Structure dimension. Carpenter and Huston-Stein (1980) operationally define Structure as "the availability of adult models or direct feedback and instruction, (i.e., guidelines, rules, or suggestions about appropriate performance)" (p. 863). With this concept in mind, examination of the plot revealed evidence that toys low in structure aligned at the bottom of the graph (play-doh and painting set) and those toys high in structure were aligned at the top of the graph (puzzle). 
Toys found in the middle of the graph (truck, carpenter set, baseball, blocks, sewing kit, jump rope, and doll) manifest some structure, but not as much as a puzzle.

As expected, one of the dimensions resulted in a Gender dimension. Dimension 4 was interpreted as Gender because those toys traditionally sex-typed as masculine (truck, carpenter set, blocks, and baseball) were all closely aligned at the top of the graph. Additionally, those toys traditionally sex-typed as feminine (doll, sewing kit, painting set, and jump rope), according to previous research, were closely aligned at the bottom of the graph.

The final dimension seemed to warrant a label of Age. Blocks, puzzles and play-doh, for example, are toys a small child would play with. Toys that clumped together in the middle of the graph (painting set, jump rope, baseball, doll, and truck) are more likely to be engaged in by at least a little older child. And finally, toys such as a sewing kit and a carpenter set are activities more likely to be engaged with by an older child who has developed better fine motor skills.

CORRELATIONS OF INDSCAL DIMENSIONS WITH MEAN RATINGS ON EIGHT BIPOLAR SCALES

In an effort to substantiate the above interpretations, mean ratings of the bipolar scales were used with the 
dimension coordinates to obtain correlations of the scales and each dimension. The mean bipolar scales are presented in Table $\mathrm{V}$ and the resulting correlations are presented in Table VI. These correlations provide additional support for the interpretations given to the dimensions.

The first dimension, Productive Play, correlates most highly $(r=.829)$ with the mean ratings on the "Activity" scale (i.e., fine and gross motor movements). Productive Play was not one of the bipolar scales listed and, therefore, Productive Play could not be related to any of the bipolar scales. Davidson (1983) suggests that when an alternate interpretation is viable, it should be reported. Thus, while dimension 1 was labeled Productive Play (see Interpretation of Dimensions, p. 44), an equally plausible alternative interpretation for this dimension could be Activity, defined here as fine vs. gross motor movements. Those toys that align on the left-hand side of the graph (painting set, carpenter set, sewing kit, puzzle, play-doh, and blocks) generally require finer motor movements than those toys aligned on the right-hand side of the graph (doll, truck, baseball, and jump rope). However, this a generalization. There are times when playing with a doll also requires fine motor movements, such as tying bows in a doll's hair.

The second dimension, Social, correlates most highly $(r=.724)$ with the mean ratings on the "Sociability" scale. 
Again, this would be expected given that the baseball and the jump rope (aligned at the top of the scale) are generally played with in larger groups; thus, these toys possess more of the Sociability attribute than those toys on the lower half of the graph. Toys on the lower half of the graph are generally played with in smaller groups (painting set, carpenter set, sewing kit, puzzle, play-doh, blocks, truck, and doll). The doll and the truck, however, are toys children typically carry with them wherever they go: The GoAnywhere toys. These two toys are characteristically played with either alone or in small groups.

The third dimension, structure, correlates very nicely $(r=.788)$ with the mean ratings on the "Structure" scale, thus substantiating the previous interpretation. Toys that can be played with and manipulated only one way (i.e., fitting into structures created by others) are closely aligned at the top of the graph (puzzle) and those toys having many, if not an infinite number of possible manipulations (i.e., ability to create structure), are closely aligned on the bottom of the graph (play-doh and painting set).

The fourth dimension, Gender, is highly correlated with the mean ratings on two bipolar scales: Gender $(r=.862)$ and Texture $(r=.746)$. Toys that previous research has found to be sex-typed as masculine are grouped together and those toys typically sex-typed as feminine are grouped 
together; however, on opposing sides of the dimension. This pattern of results lends credence to the interpretation of Gender. Regarding Texture, an examination of Figure 4 suggests that masculine-sex-typed toys tend to be harder whereas feminine-sex-typed toys tend to be softer. This is a logical result given that toys traditionally sex-typed for girls are typically made of softer materials such as supple fabrics and pliable plastics. And those toys traditionally sex-typed for boys are characteristically made of harder materials, such as wood, metal, and hard plastic.

And finally, dimension five, Age, does not correlate highly with the means on any of the bipolar scales because Age was not one of the bipolar scales listed. However, the interpretation is supported by the fact that it failed to correlate with any of the existing bipolar ratings.

What is as equally important as the significant correlations found was the fact that the dimensions did not correlate with any of the other bipolar scales contrary to the dimensional interpretation.

EXAMINATION OF WEIGHTS

Recall that each individual has a weight for each dimension which represents the salience or importance of each dimension (see Multidimensional Scaling, p. 24). Examination of the ratio of the weights provides a way of 
determining the extent to which the subjects were using one dimension over another dimension while rating the dissimilarities of the toys. The mean weight ratios for all subjects are presented in Table VII. As a whole, the participants used dimension 1 (Productive Play) about 1.33 times as much as dimension two (Sociability). Participants used dimension 1 just over 2 times as much as dimension 3 (Structure). Participants also used dimension 1 about twoand-a-half times as much as dimensions 4 (Gender) and 5 (Age). And they used Sociability more than structure, Gender, or Age (about 1.5, 1.69, and 1.81 times more, respectively). They used structure, Gender, and Age about equally. The Structure:Gender ratio was 1.10 and the Structure:Age ratio was 1.2 . And finally, the ratio of Gender to Age was 1.16 .

\section{Subgroup Differences in Weights}

Attention now will be focused on subgroup differences in the relative weights of the stimulus dimensions. Using the Male/Female category as the independent variable and the ratio of the weights as dependent variables, t-tests were used to determine if males vs females (and later parents vs child care workers) used the resulting dimensions differently. The mean ratios by groups are presented in Table VII. Results showed that females used dimension 1 (Productive Play) significantly more than males when the 
ratio of dimension 1 and dimension 3 (Structure) are compared $(p>.01)$, and when dimension 1 and dimension 5 (Age) $(\mathrm{p}>.008)$ are compared.

When examining sociability, females were found to use this dimension significantly more than males when the ratio of Sociability to structure, Gender, and Age are compared $(\mathfrak{p}>.009, \mathfrak{p}>.003, \mathfrak{p}>.001$, respectively).

Thus, it appears that while males and females both used Productive Play and Sociability more than the other dimensions, women emphasize Sociability and Productive Play relatively more than men.

As far as parents versus child care workers are concerned, there are significant differences in the way these two groups use the ratio of weights. Parents used Productive Play more than Structure, and Productive Play more than Gender, in comparison to child care workers ( $\underline{q}$ > $0.014, \mathrm{Q}>.013$, respectively). Thus, structure and Gender are more salient dimensions for child care workers than for parents.

Interestingly, while both parents and child care workers used Sociability more than Gender $(p>.045)$, child care workers actually used Gender more than parents. Thus, Productive Play and Sociability were more salient for the parents in the sample and surprisingly, child care workers used Structure and Gender more than parents. One plausible explanation for the finding that parents and child care 
workers use the dimensions differently is that the child care workers were significantly younger than the parents $(\mathrm{p}>.0001)$. While child care workers have training and experience with children, they do not have children of their own and therefore do not have the same repertoire of experiences that parents have.

To ascertain whether having children affected the way a subject used the dimensions a correlational analysis was used. Male and female parents were analyzed separately. It was determined that being either a female or a male parent (i.e., having one or more children) did not influence the use of the dimensions (the lowest probability was $\mathrm{Q}>$ $.196)$.

Additionally, we were interested in whether the Masculinity or the Femininity score taken from the BSRI was related to the use of the dimensions. Results confirmed that the Male score and the Female score failed to influence the subject's use of the dimensions (the lowest probability was $\mathfrak{p}>.586$ and $\underline{p}>.255$, respectively).

\section{VERIFICATION OF RESEARCH TOYS}

The frequency of each toy found in the subject's home is presented in Table VIII. Results confirmed that the toys selected for this study are toys that adults typically have in their home or day care center, thereby underscoring the 
importance of examining these particular toys. The lowest frequency found was for the sewing kit; however, there were still 51 out of 81 adults who actually have (or have had) the exact, or similar, sewing kit. The highest frequency was for the Tonka Truck, in which 78 adults had exactly, or a similar, truck in their homes or child care settings.

\section{BEM SEX ROLE INVENTORY (BSRI)}

In analyzing the BSRI, each person receives three major scores: A feminine score, a masculine score, and an androgynous score. The androgynous score is the difference between masculinity and femininity score normalized. A paired t-test revealed that there was not a significant difference between the masculine score and the feminine score $(Q>.11)$. Thus, according to the results of the BSRI (Bem, 1974), this sample as a whole was androgynous. When examining the means on just the feminine and masculine scores, females scored higher on the femininity score and males scored higher on the masculinity score, which according to Bem (1974), is the norm. 


\section{TABLE III \\ DEMOGRAPHICS FOR THE REMOVED SUBJECTS}

$\begin{array}{ccc}\text { MALE } & \text { FEMALE } & \text { FEMALE CHILD } \\ \text { PARENT } & \text { PARENT } & \text { CARE WORKER }\end{array}$

N

AGE (Mean)

YEAR IN SCHOOL (Freq)

Freshman

Sophomore

Junior

Senior

Graduate

\# Children (Mean)

AGE OF CHILDREN (Mean)

SEX OF CHILDREN (Freq)

Male

Female
11

31

2

14

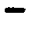

4

3

2

1.8

7.0

8

12
1

37

19

4

3

6

1

3

3

2.14

14.39

15

12

4 
TABLE IV

STIMULUS COORDINATES ON MDS DIMENSIONS

Dim 1: Dim 2: $\operatorname{Dim} 3: \operatorname{Dim} 4: \operatorname{Dim} 5$ : Productive Social Structure Gender Age Play

PS

$\begin{array}{lllll}-0.9192 & -0.0093 & -1.6078 & -1.0473 & -0.0451\end{array}$

BB

1.1116

1.8066

0.0327

$0.5119-0.0260$

DL

$$
1.3539-1.2686
$$

0.6530

$-1.2514$

0.3074

PD

$-0.4792-0.3645$

$-1.7055$

$-0.5580$

$-1.2320$

PZ

$-0.7894-0.3364$

1.7703

0.1648

$-1.2756$

CS

$-0.8994$

$-0.0985$

$-0.1420$

1.2355

1.5674

SK

$-0.9075-0.2780$

0.5328

$-1.1381$

1.5652

TR

$1.4404-0.9180$

$-0.4291$

1.4534

0.5030

JR

0.9170

1.9324

0.6150

$-0.5811$

$-0.1043$

BK $-0.8281-0.4656$

0.2805

$1.2104-1.2599$

Key: PS - Painting set

$$
\begin{aligned}
& \text { BB - Baseball } \\
& \text { DL - Doll } \\
& \text { PD - Play-Doh } \\
& \text { PZ - Puzzle } \\
& \text { CS - Carpenter Set } \\
& \text { SK - Sewing Kit } \\
& \text { TK - Truck } \\
& \text { JR - Jump Rope } \\
& \text { BK - Blocks }
\end{aligned}
$$




\section{TABLE V}

MEAN RATINGS OF TEN TOYS ON EIGHT BIPOLAR SCALES $\begin{array}{llllllllll}\text { PS } & \text { BB } & \text { DL } & \text { PD } & \text { PZ } & \text { CS } & \text { SK } & \text { TK } & \text { JR } & \text { BK }\end{array}$

Color $\begin{array}{llllllllll}7.91 & 4.65 & 2.60 & 7.25 & 8.04 & 8.30 & 4.37 & 7.06 & 4.96 & 7.67\end{array}$ Depth $\quad 4.35 \quad 7.11 \quad 8.38 \quad 6.91 \quad 2.33 \quad 7.80 \quad 3.44 \quad 8.49 \quad 4.79 \quad 7.61$ Gender $\quad 4.90 \quad 6.11 \quad 3.09 \quad 4.95 \quad 4.95 \quad 6.22 \quad 3.34 \quad 6.46 \quad 4.12 \quad 5.30$ Shape $\quad \begin{array}{llllllllllll}5.18 & 1.08 & 1.58 & 2.00 & 5.87 & 5.03 & 6.28 & 7.19 & 2.61 & 6.76\end{array}$ $\begin{array}{lllllllllll}\text { Social } & 2.38 & 6.11 & 2.06 & 2.91 & 2.05 & 2.09 & 1.64 & 2.40 & 3.24 & 2.86\end{array}$ Structure $6.62 \quad 4.30 \quad 4.75 \quad 7.69 \quad 2.03 \quad 6.17 \quad 3.19 \quad 5.09 \quad 4.28 \quad 7.35$ Texture $\quad 6.12 \quad 5.38 \quad 3.16 \quad 1.56 \quad 8.09 \quad 6.83 \quad 3.91 \quad 8.49 \quad 3.51 \quad 8.37$ Activity $2.06 \quad 7.19 \quad 4.93 \quad 3.37 \quad 2.17 \quad 4.86 \quad 1.88 \quad 6.65 \quad 7.81 \quad 3.22$

$$
\begin{aligned}
& \text { Key: } \text { PS - Painting Set } \\
& \text { BB - Baseball } \\
& \text { DL - Doll } \\
& \text { PD - Play-Doh } \\
& \text { PZ - Puzzle } \\
& \text { CS - Carpenter Set } \\
& \text { SK - Sewing Kit } \\
& \text { TK - Truck } \\
& \text { JR - Jump Rope } \\
& \text { BK - Blocks }
\end{aligned}
$$




\section{TABLE VI}

CORRELATION OF INDSCAL DIMENSIONS WITH MEAN RATINGS OF TOYS ON EIGHT BIPOLAR SCALES

$\begin{array}{lccccc} & \begin{array}{c}\text { Dim 1: } \\ \text { Productive } \\ \text { Play }\end{array} & \begin{array}{c}\text { Dim 2: } \\ \text { Social }\end{array} & \begin{array}{c}\text { Dim 3: } \\ \text { Structure }\end{array} & \begin{array}{c}\text { Dim 4: } \\ \text { Gender }\end{array} & \begin{array}{c}\text { Dim 5: } \\ \text { Age }\end{array} \\ \text { Color } & -0.613 & -0.151 & -0.303 & 0.538 & -0.302 \\ \text { Depth } & 0.490 & -0.236 & -0.324 & 0.459 & 0.119 \\ \text { Gender } & 0.024 & 0.146 & -0.289 & 0.862^{*} & -0.065 \\ \text { Shape } & -0.460 & -0.444 & 0.126 & 0.419 & 0.128 \\ \text { Social } & 0.420 & 0.724^{*} & -0.107 & 0.212 & -0.226 \\ \text { Structure } & -0.199 & -0.180 & -0.788^{*} & 0.184 & -0.203 \\ \text { Texture } & -0.159 & -0.185 & 0.260 & 0.746^{*} & -0.065 \\ \text { Activity } & 0.829^{*} & 0.534 & 0.067 & 0.319 & 0.159 \\ \text { Note. }{ }^{*} \mathrm{p} & .017 . & & & & \end{array}$


TABLE VII

MEAN WEIGHT RATIOS FOR MALES VS FEMALES, PARENTS VS CHILD CARE WORKERS, AND ALL

Female Male Parent $\begin{gathered}\text { Child Care } \\ \text { Worker }\end{gathered}$

All

$\begin{array}{lll}\text { Ratio } 1: 2 & 1.35 & 1.29 \\ \text { Ratio } 1: 3 & 2.25 & 1.61 \\ \text { Ratio } 1: 4 & 2.62 & 1.83 \\ \text { Ratio } 1: 5 & 2.72 & 1.84 \\ \text { Ratio } 2: 3 & 1.64 & 1.29 \\ \text { Ratio } 2: 4 & 1.85 & 1.28 \\ \text { Ratio 2:5 } & 1.96 & 1.42 \\ \text { Ratio } 3: 4 & 1.13 & 1.04 \\ \text { Ratio } 3: 5 & 1.23 & 1.12 \\ \text { Ratio 4:5 } & 1.16 & 1.17 \\ \text { Key: Dimension } 1-\text { Productive Play } \\ \text { Dimension } 2 \text { - Social } \\ \begin{array}{l}\text { Dimension } 3-\text { Structure } \\ \text { Dimension } 4-\text { Gender } \\ \text { Dimension } 5 \text { - Age }\end{array}\end{array}$

1.37

2.23

2.66

2.62

1.62

1.80

1.85

1.12

1.17

1.13

1.24

1.65

1.73

2.09

1.35

1.41

1.69

1.06

1.26
1.33

2.07

2.40

2.47

1.54

1.69

1.81

1.10

1.20

1.16 
TABLE VIII

FREQUENCIES OF TOYS FOUND IN ADULT HOMES AND CHILD CARE SETTINGS

Frequency Percent

Puzzle

Exactly

8

9.8

Similar

68

82.9

Absent

6

7.3

Basebal1

Exactly

14

Similar

63

Absent

5

17.1

76.8

6.1

Sewing Kit

Exactly

9

42

Similar

31

11.0

Absent

51.2

37.8

Painting set

Exactly

10

67

12.2

Similar

5

81.7

Absent

6.1

Truck

Exactly

11

67

13.4

Similar

4

81.7

Absent

4.9

Play-Doh

Exactly

61

12

74.4

Similar

9

14.6

Absent

11.0

Carpenter set

Exactly

1.2

Similar

64.6

Absent

Jump Rope

Exactly

\author{
34.1
}

Similar

36.6

Absent 
FREQUENCIES OF TOYS FOUND IN ADULT HOMES

AND CHILD CARE SETTINGS

(continued)

Blocks

Exactly

Similar

Absent

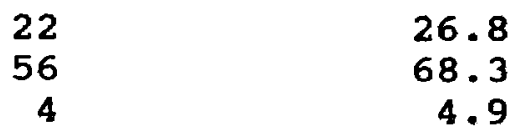

Doll

Exactly

$\begin{array}{rr}9 & 11.0 \\ 67 & 81.7 \\ 6 & 7.3\end{array}$

Note: Exactly = Exactly This Toy. Similar = similar Toy but Different Version of this Toy. Absent $=$ Do Not Have/Have Never Had this Toy. 
STRESS BY DIMENSION

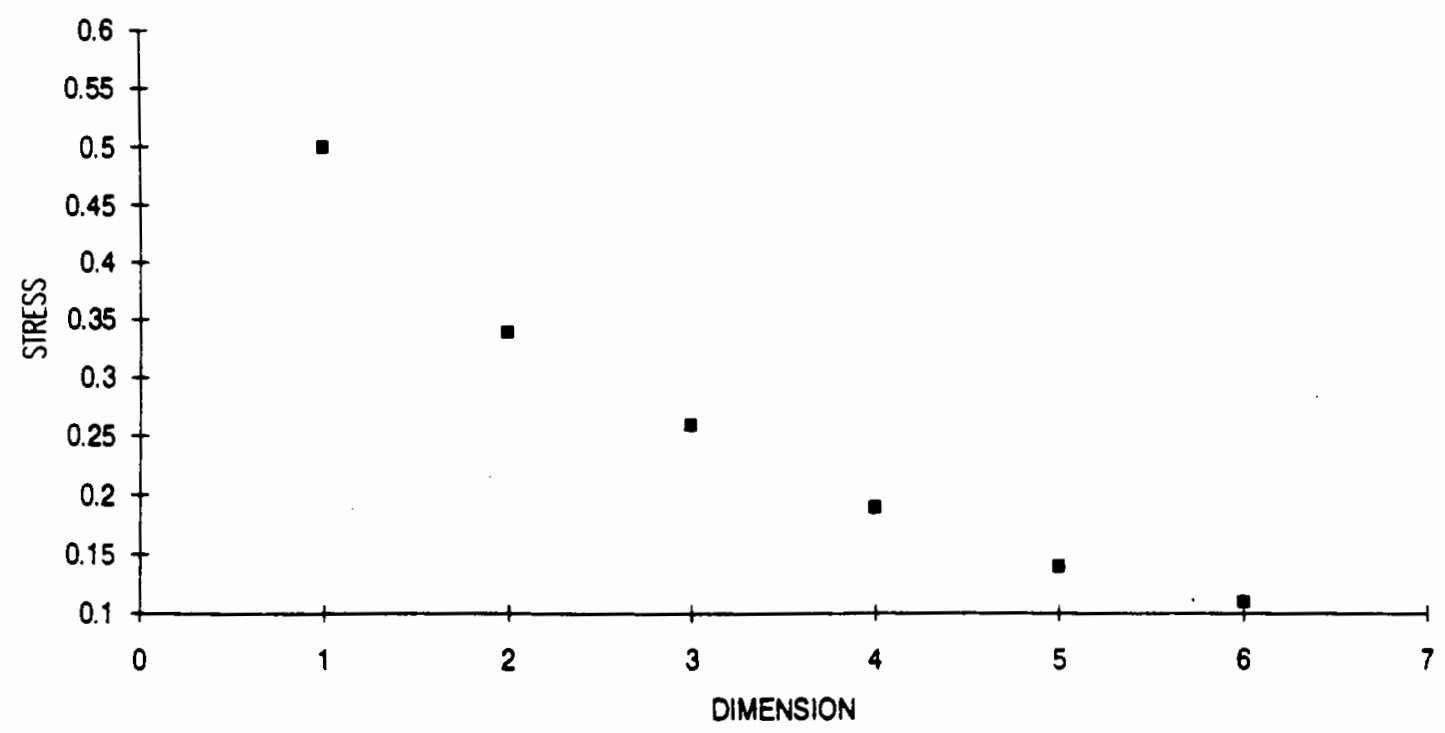

Figure 1. STRESS by Dimension plot. 
PRODUCTIVE PLAY vS SOCIABIUTY

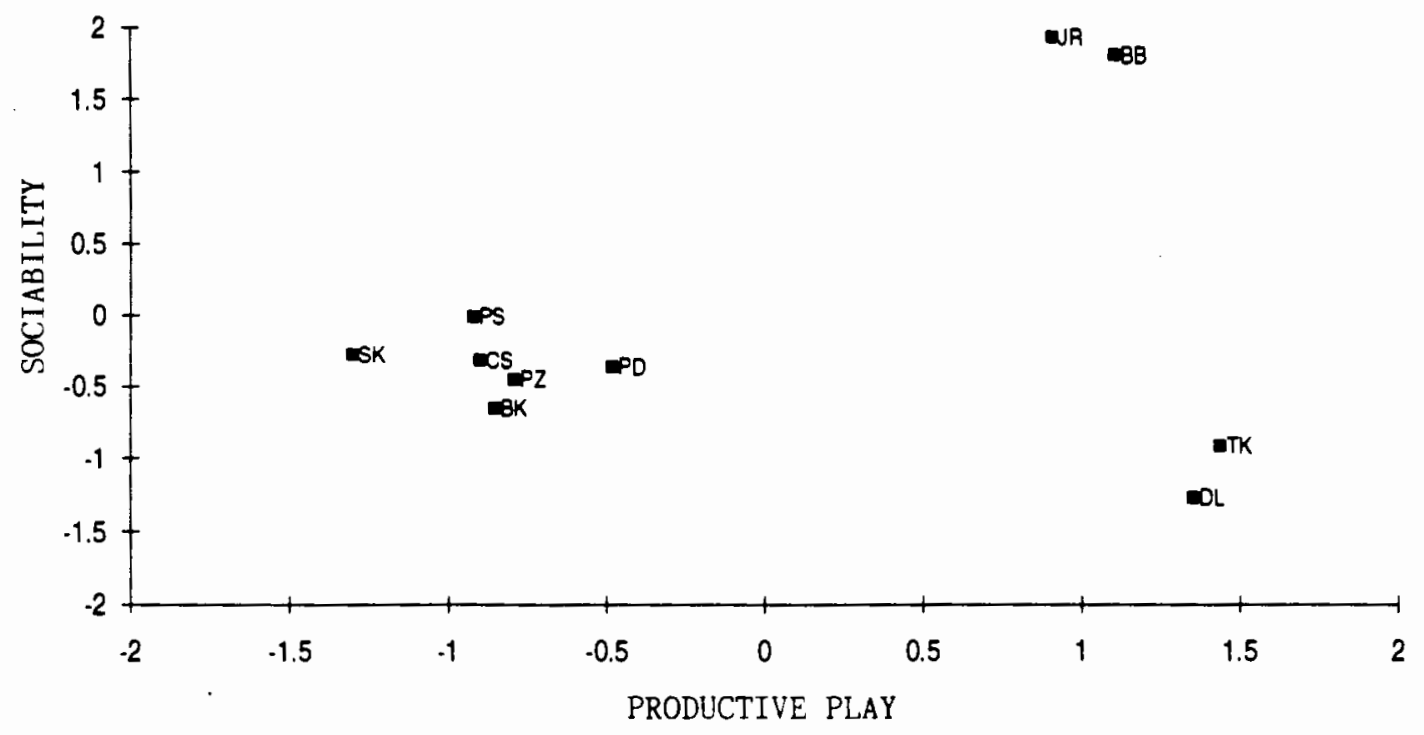

Eigure 2. Productive Play vs Sociability. 
PRODUCTIVE PLAY vS STRUCTURE

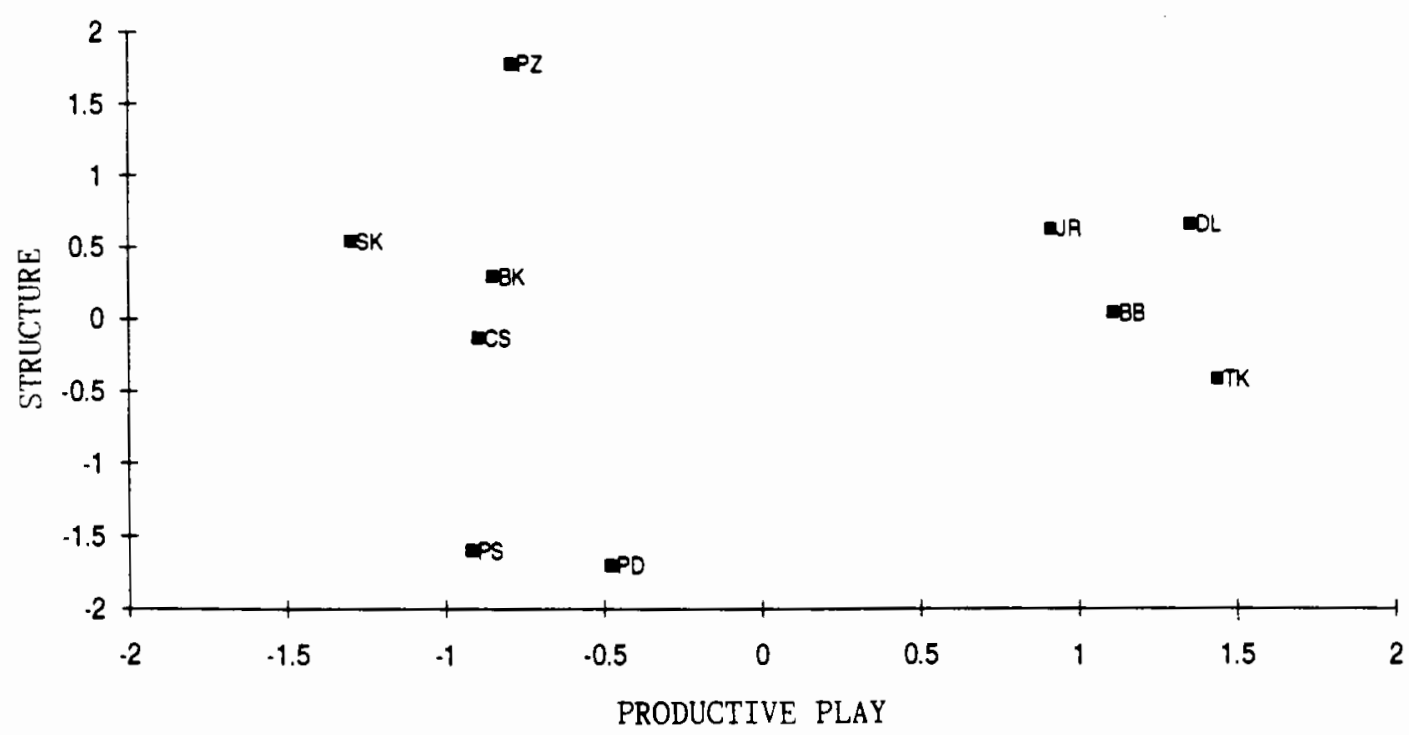

Figure 3. Productive Play vs Structure. 
PRODUCTIVE PLAY vS GENDER

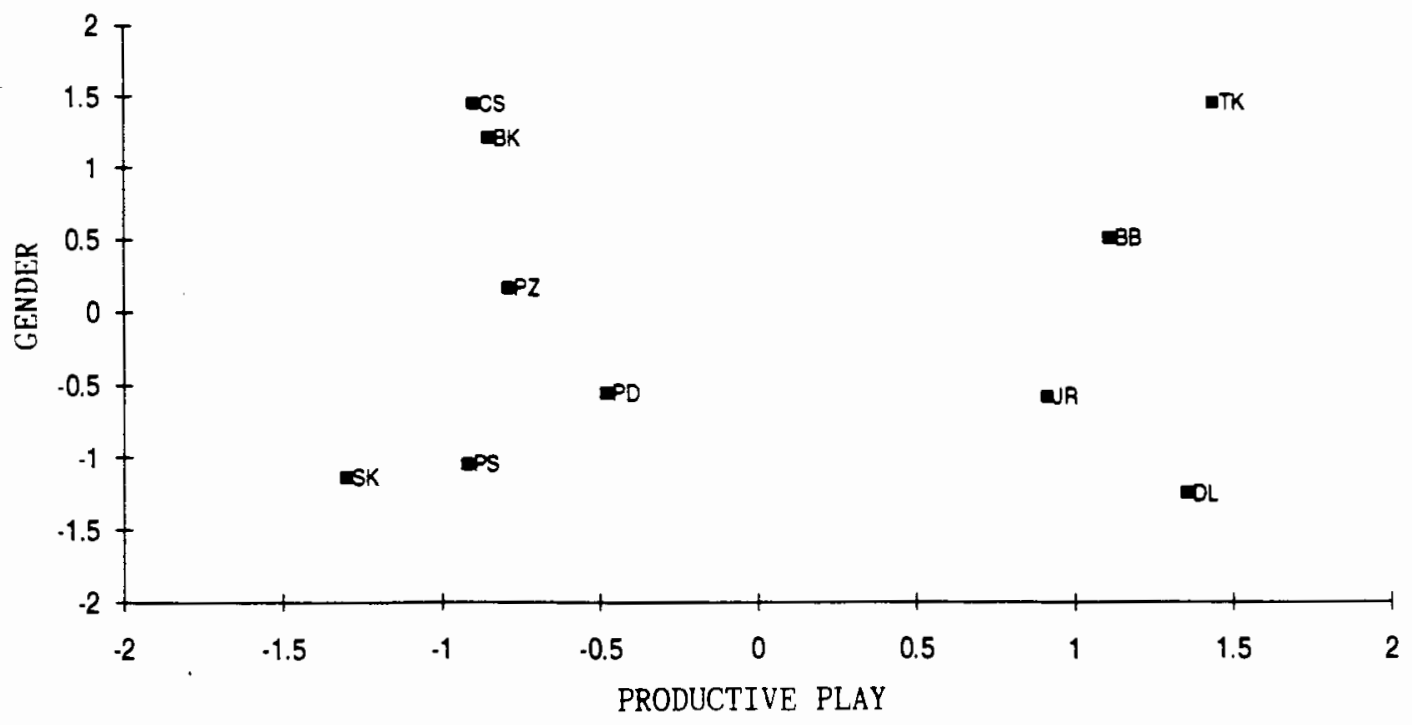

Figure 4. Productive Play vs Gender. 
PRODUCTIVE PLAY vS AGE

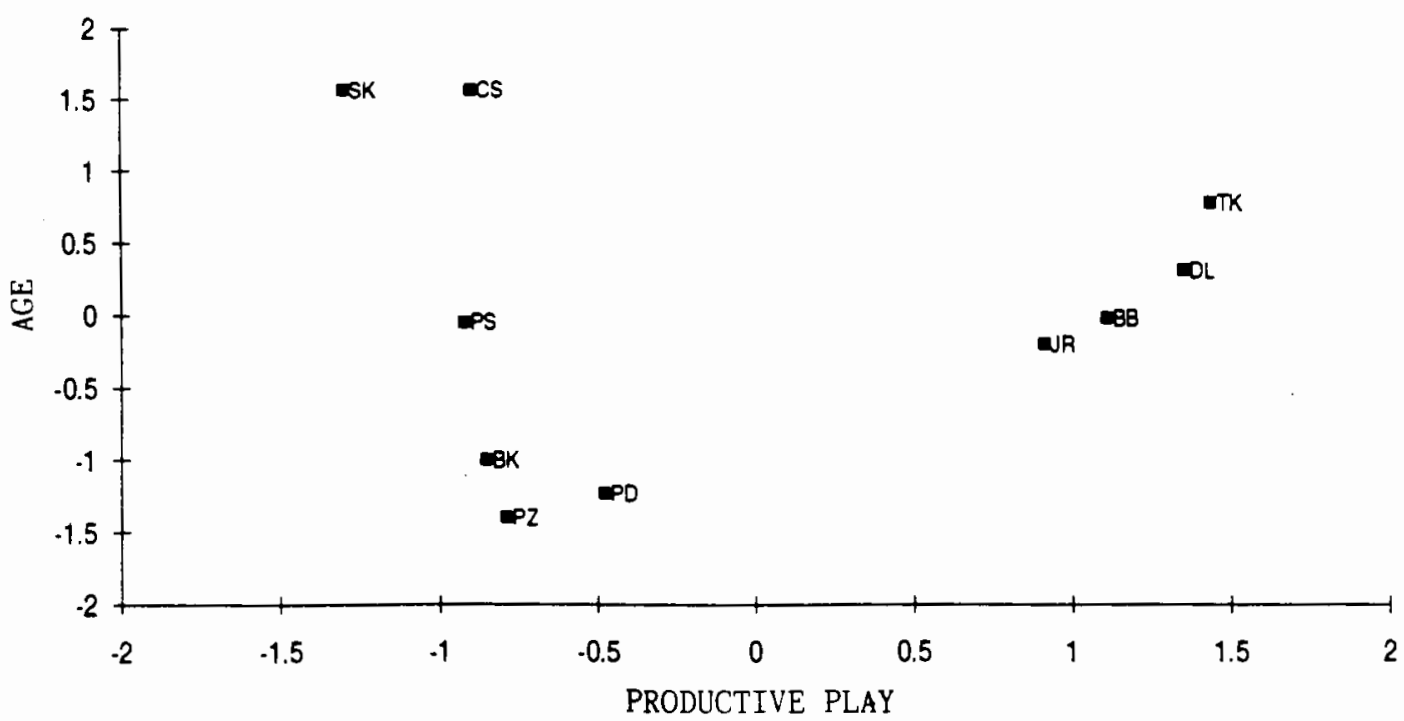

Figure 5. Productive Play vs Age. 


\section{DISCUSSION}

A multidimensional scaling analysis was performed on data collected from adult ratings of ten toys, selected to be "masculine", "feminine", or "neutral" in character. Analysis of the data revealed that five dimensions were sufficient to explain the data. The five dimensions are Productive Play, Sociability, Structure, Gender, and Age. Examination of ratio of weights revealed that the most salient dimensions for all subjects were Productive Play and Sociability. Additionally, subjects used the dimensions of Structure, Gender, and Age similarly.

\section{TOY DIMENSIONS}

Interpretation of the resulting map produced a pattern that delineated the underlying dimensions of the toys. six of the toys on the first dimension (painting set, carpenter set, sewing kit, puzzle, play-doh, and blocks) yield a product and, therefore, dimension 1 was labeled Productive Play. The label of Creativity for this dimension was briefly considered. However, the puzzle's inclusion in the list of toys that aligned on the left-hand side of the graph was something of an anomaly, given the association of 
Creativity with divergent thinking or processing. Consequently, the label of Creativity for this dimension was eschewed. However, it should be noted that there exists a precedent for calling puzzles, as well as the other five toys listed above, creative toys when operationally defined as toys that promote stretching of the mind, nurturing of concentration, problem solving and imagination (clarkeStewart, Perlmutter, \& Friedman, 1988; Feeney \& Magarick, 1984; Sylva, 1984). However, given the extensive association of Creativity with divergent thinking, the more conservative label of Productive Play was warranted. of the remaining four toys, two toys are sportsoriented (baseball and jump rope) and two toys are "TakeAnywhere" toys (doll and truck). These toys do not result in an end product and are therefore considered the less Productive toys (as defined in this study).

According to an alternative interpretation of dimension 1 (and supported by the significant correlation with the Activity bipolar rating), those toys that aligned on the left-hand side of the graph (painting set, carpenter set, sewing kit, puzzle, play-doh, and blocks) require fine motor movements. Those toys that aligned on the right-hand side of the graph, particularly the sports toys (jump rope and baseball), could be viewed as toys typically requiring greater gross motor movements. The doll and the truck are toys that potentially involve both gross and fine motor 
movements, depending on how the toy is played with. Research has continually shown that boys engage in more gross motor movement activities in playing than girls. Maccoby and Jacklin (1974) conclude that sex differences in activity level do not appear in infancy, but begin when children reach the age of social play. This suggests that socialization may be the etiology of sex differences found in the activity levels of boys and girls. Perhaps the finding that there was both a masculine- and a feminine-sextyped toy that required gross motor movements can be partially explained by the selection of toys in this study.

Dimension 2 reveals a pattern best labeled as Sociability. Trucks and dolls are toys children can take anywhere with them, and thus can be interpreted as Individual, or Take-Anywhere, toys; however, they are also toys typically played with in small groups. Thus, toys low on the sociability dimension are generally those toys played with in smaller groups, such as the play-doh, blocks, truck, and doll. Toys such as the jump rope and baseball, on the other hand, are typically played with in larger groups, especially the baseball. Research has continually shown that boys tend to play in larger groups than girls (Maccoby, 1990). Maccoby and Jacklin (1974) found that boys appear to be especially stimulated to bursts of high activity by the presence of other boys, a process not found among girls. The fact that both a masculine- and a feminine-sex-typed 
toys were found to be high in Sociability (i.e., played with in large groups) is possibly a result of the toys selected for this study.

The third dimension is termed structure. Structure has been defined by Carpenter and Huston-stein (1980) as the "availability of adult models or direct feedback and instruction (e.g., availability of guidelines, rules, or suggestions about appropriate performance)" (p. 863). Toys low in structure allow children to "create structure" whereas toys high in structure require children to "fit into structures created by others" (Carpenter \& Huston-Stein, 1980, p. 871). Toys high in structure have a narrow range of divergent uses (Wolfgang, 1983). For example, the sewing kit used in this study is highly structured; there is only one discernable, traceable pattern provided in the kit. However, blocks are low in structure; there is an infinite number of ways blocks can be arranged. Research clearly suggests that the structure of toys differs for boys and girls. Girls typically spend more time with toys high in structure, whereas boys typically spend more time with toys low in structure (Carpenter \& Huston-Stein, 1980). As a result, females are consistently deprived of vital opportunities to develop ideas and manipulate objects. Deprivation of these opportunities may result in long-term, dire consequences for girls. Studies further suggest that this discrepancy may be an antecedent to some of the 
differences in all recognized fields and levels of achievement (Carpenter \& Huston-Stein, 1980).

The forth dimension is titled Gender. Surprisingly, Gender was the third most salient dimension, and not the first. It is important to note that Gender tied for third place (with Structure and Age) in terms of the variance it explains in the data. Gender, in fact, was a less salient dimension than Productive Play and Sociability. Apparently, adults continue to recognize the sex-typing of stereotypical male and female toys, However, it is not as salient as previous research indicates (e.g., Huston, 1983).

An interesting discovery may shed new light on the rating procedure in toy preference research. Whereas previous research has asked adults to rate toys according to whether "most people" think a toy is appropriate for a girl or a boy (e.g., Schwartz \& Markham, 1985), the present study asked adults to rate the sex-appropriateness of each toy (i.e., the Gender bipolar scale) according to their "own way" of thinking. It is likely that individuals consider "others" more sex-stereotypical than themselves. Thus, when rating toys according to what others think, raters may be more likely to rate toys sex-stereotypically. However, when asked what they themselves believe, it may be that they are less likely to rate toys sex-stereotypically.

In addition to the previous explanation, it could be that Gender is a less salient cue due to the fact that this 
was overall an androgynous sample. After completing the questionnaire, many parents commented that they make active efforts not to sex-type their children's toys. But not only was the sample androgynous, it was also a homogenous sample of university students, a highly select group of individuals.

It may also be that social desirability is contributing to the Gender dimension being less salient. Given the dynamics of the situation and the visibly sex-stereotyped toys in the study, it seems possible that adults suspected the study was about gender and sex-stereotyping of children's toys, even though this information was not conveyed to the participants. They may have anticipated what the researcher considered "appropriate" (i.e., non sextyped) behavior and acted accordingly. There is some evidence for this supposition in the bipolar rating data: the mean bipolar ratings for Gender exhibited less variability than the other seven bipolar scales. In fact, for the Gender bipolar scale, the lowest mean was 3.09 for the doll and the highest mean was 6.46 for the truck. Gender was still a dimension these adults used; however, for whatever reason, it was not as salient as other cues.

The fact that texture correlated significantly with the Gender dimension is reasonable given that girls' toys tend to be the softer toys whereas boys' toys are typically made of harder, rougher materials. Again, a dichotomy of 
experience results from children receiving and playing with different types of toys. Given that sex-typed toys promote the development of different cognitive abilities, it is likely that the dichotomous experiences result in deleterious effects for boys and girls.

Dimension 5 is termed Age. Undoubtedly, adults use Age as a cue when considering the appropriateness of a toy for a child. This result is expected given that children's capabilities and interests change with age. As children develop, it is likely that their interests become centered on more adult-like activities; thus we see a shift in the desire to play with blocks to play with a carpenter set.

Now that the dimensions have been delineated, it is appropriate to discuss the toys themselves (see Figure 6 for a diagram of the toy dimensions for each toy). As hypothesized, two neutral, four feminine- and four masculine-sex-typed toys resulted. The two neutral toys in this study, the puzzle and the play-doh, have several dimensions in common. They both loaded high on the Productive Play dimension (or alternatively, they both require fine motor movements). However, these two toys, characteristically enjoyed by young children, diverge on the structure dimension; puzzles are high in structure whereas play-doh is low in structure. Additionally, these two toys are not entirely neutral. While they are both in the middle of the Gender dimension, the puzzle is more closely aligned 
with the masculine-sex-typed toys and the play-doh is more closely aligned with the feminine-sex-typed toys.

The toys traditionally considered, and identified in the research as, feminine-sex-typed are painting sets, dolls, sewing kits, and jump ropes. The results of this study confirmed this premise once again. The painting set loads highly on the productive Play dimension and typically requires fine motor movements. It is low in sociability and Structure and is typically used by a child at least in his/her middle-childhood years.

According to the results of this study, dolls are the most highly feminine-sex-typed toys. Children in their middle-childhood years would characteristically be in possession of a doll, a "Take-Anywhere" toy, that can be played with individually or in a small group. Dolls are high in structure and low in Productive Play. However, studies have found that pretend materials like dolls promote rich and complex play (Clarke-stewart, Perlmutter, \& Friedman, 1988; Feeney and Magarick, 1984).

A sewing kit is a highly structured toy that also loaded highly on the Productive Play dimension, but low in Sociability. Sewing kits are generally enjoyed by older children who possess the manual dexterity to perform this type of activity.

The jump rope did not load highly on the Productive Play dimension, and in fact, is a very structured toy. 
Additionally, jump ropes are high in Sociability and do require more gross motor movements than fine motor movements. Generally, children at least in their middlechildhood years would play with a jump rope.

As mentioned, four masculine-sex-typed toys resulted. The four toys included blocks, carpenter set, truck, and baseball. Baseball is a sports toy that does not load highly on the Productive Play dimension. Baseballs do demand gross body movements. It is an activity high in Sociability and Structure that is typically played with by children in their middle-childhood.

Trucks are also toys played with by children in their middle-childhood. Trucks did not load highly on the Productive Play dimension, and in fact, are somewhat structured. They can be considered as "Go-Anywhere" toys that are played with individually or in small groups. Trucks potentially require both fine and gross motor movements. For example, fine motor movements are required to place the "man" (i.e., figure) into the cab of a truck. The carpenter set and the truck were equally the most highly masculine-sex-typed toys. Carpenter sets loaded highly on the Productive Play dimension even though the Structure is mid-range. Carpenter sets require both fine and gross motor movements and are generally played with in small groups by older children.

Blocks, too, are considered toys that children play 
with in small groups. While being somewhat structured, blocks loaded highly on Productive Play. Additionally, blocks require fine motor movement. And blocks are typically enjoyed by even very young children.

Thus, about half the masculine- and half the femininesex-typed toys were associated by subjects with both of the dimensions labeled Productive Play and Sociability. The feminine-sex-typed toys are somewhat more structured as suggested by Carpenter and Huston-Stein (1980). And finally, most of the toys used in this study are for children in their middle-childhood period.

Figure 6 contains a diagram that summarizes the groups of dimensions characterizing each toy. Examination of this diagram reveals some important information. First, it is interesting to note that, with one exception (the sewing kit), for every group of dimensions there is both a masculine- and a feminine-sex-typed toy. Given previous research suggesting that masculine- and feminine-sex-typed toys are very different, this was a surprising result. Additionally, from examining the toys in these groups of dimensions there is evidence that the majority of toys are low in Sociability, particularly those toys that yield a product. Given our society's emphasis on individualist achievement it is perhaps not surprising that more Productive Play toys that are also highly Social are not available to children. Given Japan's cultural emphasis on 
teamwork it would be interesting to do a cross-cultural study with Japan to discover whether Japanese toys exist that are both high in Productive Play and high in Sociability.

But what is perhaps even more interesting than which toys are associated with each group of dimensions in the diagram is the fact that there is an absence of toys in many of these groups of dimensions. This suggests that the toy industry is tapping only a small range of permutations in the underlying dimensions that characterize children's toys. It may be that children are missing out on some vital experiences that could be facilitated through play with toys in these empty categories. For example, it seems likely that toys high in Productive Play, high in Sociability, and low in structure would be very beneficial for both social and cognitive development. More research is needed to discover ways of tapping the vacant toy categories found in this study.

Differences among individuals in the use of the resulting dimensions were expected. Therefore, comparisons were made between male and female respondents and between parents and child care workers. While all groups used the Productive Play dimension more than the other dimensions, it appears that the Productive Play dimension is even more salient for women and parents than for men and child care workers. Above and beyond these differences, males use the 
dimensions of Structure, Age, and Gender more than females, as would be expected (Fein et al., 1975). And child care workers use the dimensions of structure and Gender more than parents.

It is surprising to find that child care workers use the Gender dimension as compared to Productive Play, and as compared to Sociability, significantly more than parents, even though this sample was characterized as androgynous. This is perplexing, also, in that child care workers are trained and encouraged to promote cross-sex-typed play, and they are exposed to more nonsex-typed behavior in children than parents. Perhaps the younger age of the child care workers actually fosters the use of Gender as a cue.

The bipolar ratings selected for this study are helpful in aiding and substantiating dimension interpretations. However, it is generally expected that not all of the bipolar ratings will be significantly correlated with the dimensions. And, in fact, some of the bipolar scales did not emerge as dimensions in the multidimensional scaling process. For example, the bipolar scale Depth failed to manifest. Depth deals with the dimensionality of the toys [i.e., flatness (two-dimensional) vs height-length-depth (three-dimensional)]. It is probable that depth failed to manifest because it is such a subtle cue. Indeed, it is rarely addressed in the literature on children's toys. Yet there is research to suggest it is an important feature in 
the development of certain cognitive skills. Studies suggest that the fact that girls' toys are characteristically flat whereas boys' toys are usually three-dimensional may be an antecedent to the divergent cognitive abilities exhibited by girls and boys, particularly visual-spatial ability. Studies continually show that boys have greater visual-spatial ability than girls. However, when girls are provided with training exercises they meet or exceed male scores (Serbin \& Connor, 1979; Sprafkin et al., 1983). These findings suggest that discrepant visual-spatial scores of boys and girls may be the result of learning and not innate differences. Additionally, the bipolar scale shape failed to manifest. Again, this is likely the result of shape being such an extremely subtle cue that parents are unaware of it. Interestingly, the shape of toys as it relates to masculinity and femininity is rarely discussed in the literature. Nonetheless, studies are finding that angular lines are representative of masculinity and rounded curves are representative of femininity (Leinbach, 1992). For example, dolls are comprised of rounded curves whereas blocks consist of angular lines.

The bipolar scale Color also failed to manifest as a dimension. Studies have produced evidence suggesting that color is a salient cue in the gender-typing of toys (FisherThompson, 1990; Leinbach \& Hort, 1989). Boys' toys are 
typically brightly colored, whereas girls' toys are typically pale in color. This was certainly true of the toys utilized in this study. Given the salience of color, I am at a loss to explain why this dimension failed to manifest in the present results.

IMPLICATIONS: TOY MARKETING, INTERVENTION, AND FUTURE RESEARCH

Color is no less suggestive when it concerns the packaging of children's toys. An informal examination of the toy packages for the research stimuli revealed differences in the color of the packaging. The blocks and carpenter set packages, for example, were sexstereotypically brightly colored (as were the toys), whereas the packaging for the sewing kit and the doll were sexstereotypically pale in color. However, a trade magazine for the toy industry, Playthings, reports that children more often respond to red and yellow packages, while adults favor blue (Goldberg, 1989).

Color appears also to be a salient cue in toy store displays. An impromptu visit to six local toy stores revealed that toy displays in four of the toy stores were grossly sex-stereotypically segregated. The toys in the less expensive (i.e., discount) toy stores were more stereotypical than those in the more expensive toy stores. 
The discount toy stores have separate aisles for girls' toys of all ages, which are dominantly packaged in pale colors such as pink and white. The remaining aisles are reserved exclusively for boys' toys, in which the packaging of young boys' toys is brightly colored, whereas the middle, and particularly the older boys' toys packaging, is mainly dark in color.

The two more expensive toy stores mainly sold import toys from Europe, and had somewhat less stereotypical displays. In addition, the vast majority of the toys were brightly colored with one exception: the doll display. This was decorated in white and pastels just as the less expensive toy store doll displays. A spontaneous conversation held with a sales clerk at one of the expensive toy stores revealed that the company, and the manager of that store, was adamantly opposed to stereotyping children's toys. The manager had planned the design of the store to reflect this belief. As noted, this was an informal excursion. However, it would be interesting to investigate empirically whether there are educational and socioeconomic differences in the toy purchasing practices of adults. Clearly, the majority of toy stores are designed to fuel and maintain stereotyping. The bottom line is economics and this practice sells toys.

As we have just observed, the color of children's toy packages is a salient cue for purchasers. It is perhaps no 
less revealing to examine the figures typically found on toy packages. Many packages feature a solitary human face or a child playing with the toy. This is because toy packages have generally been designed by adults to communicate to other adults. However, today children are accompanying their parents to the toy stores. A study by Goldberg (1989), and reported in Playthings, revealed that parents love to see a photo of a child on a toy package, but that children generally ignore these photos. Instead, children are attracted to bright graphic shapes that are either unfinished or open. Nonetheless, of those packages with models, the masculine-sex-typed toy packages show a young boy, whereas the feminine-sex-typed toy packages display a young girl. These depictions of sex-appropriate children produce yet another prominent cue to purchasers as to which toy is appropriate for which sex. While my contention is not scientifically supported, informal investigations suggest that boys have less of a tendency to play with a toy containing a female figure on the package. Thus, it is my assertion that placing a sex-appropriate figure on the package actually serves to initiate, amplify, and perpetuate the stereotyping of children's toys.

The toy industry is no less responsible for the perpetuation of stereotypes than the toy stores. And in fact, it is probably more so since they are the inventors and marketers of children's toys. The toy industry savagely 
promotes sex-stereotypical play and behaviors, thereby continually undermining the psychological health and cognitive development of young, impressionable girls with lasting, detrimental consequences. This is also true to some extent for boys. As far back as 1951 child rearing books discussed the use of toys to aid in the development of "creeping" (i.e., crawling), and later, gross motor movement (Better Homes and Gardens Baby Book). Research today has demonstrated that toys have the capacity to aid in developing more than crawling and gross motor movement. With the important dimensions delineated in this study, along with knowledge from previous research of the types of cognitive abilities toys promote, toy companies should take greater responsibility in developing and marketing toys that facilitate positive and constructive physical, social, psychological, and cognitive development in young girls.

However, presently, not all toys are beneficial. Many feminine-sex-typed toys, such as vanity sets, suggest that girls are passive self-admirers. Sadly, research has shown that praise for appearance from teachers is the only area in which girls receive more attention than boys (AAUW, 1992). Toys such as Barbie Dolls further advance the belief that beauty is only skin deep (i.e., that beauty is the only important attribute a girl possesses). When girls fail to measure up to this inanimate object (i.e., Barbie Doll), they wonder what is wrong with them. Cathy Meredig, 
president of High Self-Esteem Toys, is attempting to rectify this situation. This new toy company has developed a doll similar to fashion dolls but with normal body proportions. It is imperative that we have more innovative, responsible entrepreneurs to develop and market this type of toy and thereby, overcome the esteem-eroding power of society.

As we have seen, the socialization of children is a subtle process that begins very early. Female professors at the University of Michigan were asked about their aspirations for their children. Most professors commented that they desired equal success for their sons and daughters. However, more specific probing revealed that it was more important for their sons to be successful and educated than their daughters (Hoffman, 1977).

Studies are reporting that the attitudes and behaviors which parents, peers, teachers and the media stress for girls may be intellectually stifling. A major theme in the women's liberation movement is a rejection of mutually exclusive conceptualizations of sex roles and the struggle for equal accessibility for both sexes to all occupations and activities (Flerx et al., 1976). Promoting androgyny in girls may provide them with more opportunities for intellectual stimulation and development (Tracy, 1990). For example, androgyny has been positively correlated with selfesteem, supporting the claim that individuals who combine the positive elements of masculinity and femininity are best 
adapted for healthy psychological functioning (Bem, 1975; Huston, 1983). Increasing sex role flexibility has also been associated with greater life satisfaction and more successful aging for older adults (Windle, 1987). But it can begin in childhood.

The concern that promoting androgyny will reduce the differences between the sexes to such an extent that the sexes will become integrated is unfounded. Evidence suggests that adolescent and adult women who enter male domains of career involvement perceive themselves as more "masculine", though not necessarily less feminine, than those who follow traditional female life patterns (Huston, 1983; Metzler-Brennan et al., 1985).

There are some precautions parents (and others) can take to encourage self-esteem and academic achievement in young girls that could ultimately result in greater choices and opportunities. One of the most important and lasting precautions involves teaching female children independence. Research suggests that this can begin at a very early age with something as simple as giving female children the autonomy to choose their clothes.

Research has demonstrated that it is never too late to modify existing traditional stereotypes. Studies continue to reveal that children exposed to several counterstereotypical models, particularly if these models are in the majority, can produce imitation of nontraditional 
behavior (Huston, 1983). Children whose mothers are employed outside the home have less stereotypical sex-role perceptions than children whose mothers do not work for pay outside the home (Perloff, 1977; Reid \& Stephens, 1985). Unfortunately, girls have little exposure to positive role models in books and films. Therefore, it is a parent's responsibility to inspire young children with a trip to the library, reading stories featuring gutsy little girls and women in history (Bem, 1983; Reid \& Stephens, 1985). Studies are now calling for new classroom materials, asserting that "Boys and girls should be able to study women Nobel Prize winners in addition to Betsy Ross sewing the flag" (AAUW, 1992).

Preschoolers can benefit from exposure to a range of activities, including indoor and outdoor activities. Studies consistently show that the out-of-doors is typically considered boys' domain. Boys are given the freedom to explore, experience, and manipulate their world. Parents are more protective of their girls, characteristically keeping them indoors and denying them vital exploratory experiences. But it is essential that girls be given these opportunities. Also beneficial for girls is to increase their range of toys and activities. Provide them with trucks (i.e., masculine-sex-typed toys) as well as dolls (i.e., feminine-sex-typed toys) (Bem, 1983).

It is critical that we encourage young girls to 
develop math, science, and computer skills (Reid \& Stephens, 1985). Maccoby and Jacklin (1974) have dispelled the myths that girls are better at rote learning and simple repetitive tasks, as well as the myth that boys are more analytical. Research consistently shows that the average working woman's salary still lags far behind the average man's salary, as it did twenty years ago. In fact, the average female college graduate continues to earn less than a man with no more than a high school diploma (just as she did in the 50's) (Faludi, 1991). Studies suggest that girls who master math, science, and computer skills will greatly increase their odds of becoming successful, confident, high-wage-earning women of tomorrow (Reid \& Stephens, 1985).

Teachers have the capacity to bridge the gender gap. This can be accomplished by something as simple as grouping children in ways other than "boys on one side, girls on the other." Teachers can arrange classrooms to eliminate invisible barriers (i.e., "the separation of toy trucks and building blocks from housekeeping toys"). As was already mentioned, curricula are needed that contain stories about both males and females. And finally, it is advantageous for teachers to make comments to girls on characteristics other than girls' appearances (Nilson, 1977). Research has established that teachers possess the power to accomplish this important task.

Research would benefit from delineating additional 
means for encouraging cross-sex-typed play. For example, does featuring a cross-sex-typed model on a toy package encourage cross-sex-typed play? Additionally, research could examine whether something as simple as changing the texture or color of a toy would encourage its cross-sextyped use by children. Research is currently underway on this topic with promising results (Hort, 1992). If this line of research proves fruitful, the toy industry and parents will have a potentially simple and powerful means to encourage girls and boys to play with cross-sex-typed toys, thus exposing both sexes to new, and various, experiences. The five resulting dimensions of toys discovered in this study are undoubtedly important in the selection of toys for children. It is perplexing why this study found the same number of masculine- and feminine-sex-typed toys loading equally on the productive play and structure dimensions. Given previous research (e.g., Carpenter \& Huston-Stein, 1980), it was suspected that masculine-sextyped toys would load low on structure and feminine-sextyped toys would load high on structure. However, the present study found that an equal number of masculine- and feminine-sex-typed toys loaded highly on the structure dimension. Structure is a particularly important dimension because it is believed to facilitate cognitive development (Carpenter \& Huston-Stein, 1980). Clearly, more research is necessary to determine whether masculine-sex-typed toys are 
less structured than feminine-sex-typed toys.

It is plausible that the cognitive differences found between girls and boys could be partially attributable to the different play styles exhibited by each gender rather than the characteristics of the toys. The results of this study clearly suggest that boys' and girls' toys are not as divergent with respect to structure as previous research proposes. Additionally, the social climate may be different today than it was ten years ago. It is possible that adults are more aware of the beneficial aspects of toy play. Thus, adults may be evaluating toys on the basis of the toys' potential benefit for their children's cognitive development.

It was further surprising to discover the equal number of masculine- and feminine-sex-typed toys that loaded equally on the Productive Play dimension. Two masculineand two feminine-sex-typed toys, as well as the two neutral toys, were highly related to Productive Play. Two masculine- and two feminine-sex-typed toys, however, were not related to Productive Play. The fact that the toys that facilitate productivity loaded highly on the Productive Play dimension further illustrates the importance of this dimension with regards to cognitive development. As mentioned, a precedent exists for labeling this dimension Creativity as these toys promote complex play involving stretching of the mind, nurturing of concentration, problem 
solving and imagination (Clarke-Stewart et al., 1988; Feeney \& Magarick, 1984; Sylva, 1984). It will be imperative that researchers discern whether these toys benefit one sex more than the other, or whether both sexes are equally well served by toys that load highly on the Productive Play dimension. The results of this study suggest that opportunities for complex play are available to both sexes. However, given the sample in this study, care must be exercised in generalizing these results. While the toys in this study failed to manifest salient differences with respect to Structure and Productive Play, research continues to demonstrate that males and females are exposed to different types of toys, resulting in dichotomous cognitive experiences (e.g., Carpenter \& Huston-Stein, 1980; Serbin \& Connor, 1979; Sprafkin et al., 1983; Tracy, 1990).

Parental factors have been shown to be the most predictive of girls' achievement in nontraditional areas (Reid \& Stephens, 1985). Thus, making parents aware of the consequences of their behavior and the basis for their toy purchasing decisions (i.e., masculine- and feminine-sextyped toys) may result in parents providing more equivalent experiences for girls and for boys. It is likely that raising parental awareness, as well as the awareness of peers, teachers, the toy industry, and society in general, will foster the development of skills in both sexes. This could produce equitable opportunities for boys and girls 
scholastically, in their career alternatives and aspirations, as well as in their social lives. 


$$
\begin{array}{ll}
\text { High structure } & \text { Male } \\
\text { Neutral } \\
\text { Female }
\end{array}
$$

High Sociability
Male

Neutral

Fenale

High

Productive

Play

Low Structure

Male Blocks, Carpenter set

Neutral Play-Doh

Female painting set

Male

Neutral Puzzle

Female Sewing Kit

Low Sociability

High Structure

Low

Productive

play

High structure

Male Baseball

Neutral

Female Jump Rope

High Sociability

Low structure

Male

Neutral

Fenale

High structure

Male Truck

Neutral

Female Doll

Low Sociability

$\begin{array}{ll}\text { Low Structure } & \text { Male } \\ \text { Neutral } \\ \text { Female }\end{array}$

Figure 6. Diagram of Toy Dimensions 
Almqvist, B. (1989). Age and gender differences in children's Christmas requests. Play \& Culture, $\underline{2}$, 2-19.

American Association of University Women (AAUW) (1992). How Schools Shortchange Girls. AAUW Educational Foundation and National Education Association.

Ashton, E. (1983). Measures of play behavior: The influence of sex-role stereotyped children's books. Sex Roles, $\underline{9}(1), 43-47$.

Baird, J. C., \& Noma, E. (1978). Fundamentals of scaling and psychophysics. New York:; Wiley.

Balaban, T., \& Cooper, J. (1981). Gender constancy and the effects of sex-typed televised toy commercials. Child Development, $\underline{52}, 667-673$.

Bandura, A. (1977). Social learning theory. New Jersey: Prentice-Hall.

Bem, S. L. (1974). The measurement of psychological androgyny. Journal of Consulting and Clinical Psychology, $\underline{42}(2), 155-162$.

Bem, S. L. (1975). Sex role adaptability: One consequence of psychological androgyny. Journal of Personality and Social Psychology, 31(4), 634-643.

Bem, S. L. (1981). Gender schema theory: A cognitive account of sex typing. Psychological Review, 88(4), 354-364.

Bem, S. L. (1982). Gender schema theory and self-schema theory compared: A comment on Markus, Crane, Bernstein, and Siladi's "self-schemas and gender." Journal of Personality and Social Psychology, $\underline{43}(6), 1192-1194$. 
Bem, S. L. (1983). Gender schema theory and its

implications for child development: Raising genderaschematic children in a gender-schematic society. Signs: Journal of Women in culture and Society, $\underline{8}(4), 598-616$.

Better Homes and Gardens Baby Book. (1951). Des Moines: Meredith Publishing Company.

Bronfenbrenner, U. (1986). Ecology of the family as a context for human development: Research perspectives. Developmental Psychology, 22(6), 723-742.

Caldera, Y. M., Huston, A. C., \& O'Brien, M. (1989). Social interactions and play patterns of parents and toddlers with feminine, masculine, and neutral toys. Child Development, 60, 70-76.

Carpenter, C. J., \& Huston-Stein, A. (1980). Activity structure and sex-typed behavior in preschool children. Child Development, 51, 862-872.

Carter, D. B. (1987). Sex role research and the future: New directions for research. In D. B. Carter (Ed.), Current Conceptions of Sex Roles and Sex Typing (pp. 243-251). New York: Praeger.

Carter, D. B., \& Levy, G. D. (1988). Cognitive aspects of early sex-role development: The influence of gender schemas on preschoolers' memories and preferences for sex-typed toys and activities. Child Development, 59, 782-792.

Clarke-Stewart, A. C., Perlmutter, M., \& Friedman, S. (1988). Life-long human development. John Wiley \& Sons: New York.

Connor, J. M., \& Serbin, L. A. (1977). Behaviorally based masculine- and feminine-activity-preference scales for preschoolers: Correlates with other classroom behaviors and cognitive tests. Child Development, 48, 1411-1416.

Connor, J. M., \& Serbin, L. A. (1978). Children's responses to stories with male and female characters. Sex Roles, $4(5), 637-645$.

Cordua, G. D. , McGraw, O., \& Drabman, R. S. (1979). Doctor or Nurse: Children's perception of sex typed occupations. Child Development, 50, 590-593. 
Coury, K., \& Wolfgang, C. (1984). An overview of the measurement methods of toy and play preference studies. Early Child Development and Care, 14, 217-232.

Davidson, M. L. (1983). Multidimensional Scaling. New York: John Wiley \& Sons.

Eaton, w. O., Von Bargen, D., \& Keats, J. G. ( 1981). Gender understanding and dimensions of preschooler toy choice: Sex stereotype versus activity level. Canadian Journal of Behavioral Science, 13(3), 203-209.

Edelbrock, C., \& Sugawara, A. I. (1978). Acquisition of sextyped preferences in preschool-aged children. Developmental Psychology, 14(6), 614-623.

Eisenberg, N. (1983). Sex-typed toy choices: What do they signify? In M. B. Liss (Ed.), Social and Cognitive Skills (pp. 45-70). New York: Academic Press.

Eisenberg, N., Murray, E., \& Hite, T. (1982). Children's reasoning regarding sex-typed toy choices. Child Development, $\underline{53}, 81-86$.

Eisenberg, N., Tryon, K., \& Cameron, E. (1984). The relation of preschoolers' peer interaction to their sex-typed toy choices. Child Development, 55, 1044-1050.

Fagot, B. I. (1978). Reinforcing contingencies for sex-role behaviors: Effects of experience with children. Child Development, $49,30-36$.

Fagot, B. I. (1981). Stereotypes versus behavioral judgments of sex differences in young children. Sex Roles, $\underline{7}(11)$, 1093-1096.

Fagot, B. I., \& Leinbach, M. D. (1983). Play styles in early childhood: Social consequences for boys and girls. In M. B. Liss (Ed.), Social and Cognitive Skills (pp. 93116). New York: Academic Press.

Fagot, B. I., \& Leinbach, M. D. (1987). Socialization of sex roles within the family. In D. B. Carter (Ed.), current Conceptions of Sex Roles and Sex Typing (pp. 89-100). New York: Praeger.

Fagot, B. I., \& Leinbach, M. D. (1989). The young child's gender schema: Environmental input, internal organization. Child Development, 60, 663-672. 
Fagot, B. I., Leinbach, M. D., \& Hagan, R. (1986). Gender labeling and the adoption of sex-typed behaviors. Developmental Psychology, 22(4), 440-443.

Fagot, B. I., Littman, I. (1976). Relation of preschool sextyping to intellectual performance in elementary school. Psychological Reports, 39, 699-704.

Faludi, S. (1991) . Backlash. New York: Crown Publishers.

Feeney, S., \& Magarick, M. (1984). Choosing good toys for young children. Young Children, $40(1), 21-24$.

Fein, G., Johnson, D. , Kosson, N., Stork, L., \& Wasserman, L. (1975). Sex stereotypes and preferences in the toy choices of 20-month-old boys and girls. Developmental Psychology, 11(4), 527-528.

Fisher-Thompson, D. (1990). Adult sex typing of children's toys. Sex Roles, $\underline{23}(5 / 6), 291-303$.

Flerx, V. C., Fidler, D. S., \& Rogers, R. W. (1976). Sex role stereotypes: Developmental aspects and early intervention. Child Development, 47, 998-1007.

Garvey, C. (1990). Play. Cambridge: Harvard University Press.

Gelman, S. A., Collman, P., \& Maccoby, E. E. (1986) . Inferring properties from categories versus inferring categories from properties: The case of gender. Child Development, 57, 396-404.

Gilligan, C. (1982). In a different voice: Psychological theory and women's development. Cambridge, Mass: Harvard University Press.

Goldberg, R. I. (1989, December). Good toy packaging must appeal to all. Playthings, p. 40 .

Goldberg, S., \& Lewis, M. (1967). Play behavior in the yearold infant: early sex differences. Child Development, $\underline{40}(1), 21-31$.

Haugh, S. S., Hoffman, C. D., \& Cowan, G. (1980). The eye of the very young beholder: Sex typing of infants by young children. Child Development, 51, 597-600.

Hoffman, L. W. (1977) . Changes in family roles, socialization, and sex differences. American Psychologist, 32(8), 644-657. 
Hood, K. E., Draper, P., Crockett, L. J., \& Peterson, A. C. (1987). The ontogeny and phylogeny of sex differences in development: A biopsychosocial synthesis. In D. B. Carter (Ed.), current Conceptions of Sex Roles and Sex Typing (pp. 50-77). New York: Praeger.

Hort, B. E. (1992, April). Metaphorically Gendered Traits and the Gender Typing of Toys. Paper presented at the annual meeting of the western Psychological Association, Portland, OR.

Hort, B. E., Leinbach, M. D., \& Fagot, B. I. (1991). Is there a coherence among the cognitive components of gender acquisition? Sex Roles, 24(3/4), 195-207.

Huston, A. C. (1983). Sex-Typing. In P. H. Mussen (Ed.), Handbook of Child Psychology (pp.387-467). New York: John wiley \& Sons.

Huston, A. C., Wright, J. C., Rice, M. L., Kerkman, D., and St. Peters, M. (1990). Development of television viewing patterns in early childhood: A longitudinal investigation. Developmental Psychology, 26 (3), 409420 .

Karpoe, K. P., \& Olney, R. L. (1983). The effect of boys' or girls' toys on sex-typed play in preadolescents. Sex Roles, $9(4), 507-518$.

Kohlberg, L. A. (1966). A cognitive-developmental analysis of children's sex-role concepts and attitudes. In E. E. Maccoby (Ed.), The development of sex differences (pp. 82-172). Stanford: Stanford University Press.

Kunkel, D., \& Murray, J. (1991). Television, children, and social policy: Issues and resources for child advocates. Journal of Clinical Child Psychology, 20(1), 88-93.

La Freniere, P., Strayer, F. F., \& Gauthier, R. (1984). The emergence of same-sex affiliative preferences among preschool peers: A developmental/ethological perspective. Child Development, 55, 1958-1965.

Lamb, M. E., \& Roopnarine, J. L. (1979). Peer influences on sex-role development in preschoolers. Child Development, 50, 1219-1222.

Leinbach, M. D. (1991). The beginnings of gender: What's happening before age two? Paper presented at the Biennial Meeting of the Society for Research in Child Development, Seattle, WA. 
Leinbach, M. D. (1992, April). Conventionally and metaphorically gendered parameters in children's gender judgments. Paper presented at the annual meeting of the Western Psychological Association, Portland, OR.

Leinbach, M. D., \& Fagot, B. I. (1986). Acquisition of gender labels: A test for toddlers. Sex Roles, $15(11 / 12), 655-666$.

Leinbach, M. D., \& Hort, B. E. (1989). Bears are for boys: "Metaphorical" associations in the young child's gender schemas. Presented to Society for Research in Child Development, Kansas City, Mo.

Lewis, M., \& Weinraub, M. (1979). Origins of early sex-role development. Sex Roles, $\underline{5}(2), 135-153$.

Liben, L. S., \& Signorella, M. L. (1987). Children's gender schemata. In W. Damon (Ed.), New Directions for Child Development (pp. 5-22). San Francisco: Jossey-Bass.

Liss, M. B. (1983). Learning gender-related skills through play. In M. B. Liss (Ed.), Social and cognitive Skills (pp. 147-166). New York: Academic Press.

Maccoby, E. E. (1990). Gender and relationships: A developmental account. American Psychologist, 45(4), 513-520.

Maccoby, E. E., \& Jacklin, C. N. (1974). The Psychology of Sex Differences. Stanford: Stanford University Press.

Martin, C. L. (1989). Children's use of gender-related information in making social judgments. Developmental Psychology, 25(1), 80-88.

Martin, C. L., Eisenbud, L., \& Rose, H. A. (1992, April). Children's avoidance of attractive cross-sex toys. Paper presented at the meeting of the Southwestern Society for Research on Human Development, Tempe, AZ .

Martin, C. L., \& Halverson, C. F., Jr. (1981). A schematic processing model of sex typing and stereotyping in children. Child Development, 52, 1119-1134.

Martin, C. L., \& Halverson, C. F. (1987). The roles of cognition in sex role acquisition. In D. B. Carter (Ed.), Current Conceptions of Sex Roles and Sex Typing (pp. 123-137). New York: Praeger. 
Martin, C. L., Wood, C. H., \& Little, J. K. (1990). The development of gender stereotype components. Child Development, 61, 1891-1904.

McConaghy, M. J. (1979). Gender permanence and the genital basis of gender: Stages in the development of constancy of gender identity. Child Development, 50, 1223-1226.

McGhee, P. E., \& Frueh, T. (1980). Television viewing and the learning of sex-role stereotypes. Sex Roles, $\underline{6}(2)$, 179-188.

Metzler-Brennan, E., Lewis, R. J., \& Gerrard,M. (1985). Childhood antecedents of adult women's masculinity, femininity, and career role choices. Psychology of women Quarterly, 9 (3), 371-382.

Miller, C. L. (1987). Qualitative differences among genderstereotyped toys: Implications for cognitive and social development in girls and boys. Sex Roles, 16(9/10), 473-487.

Mischel, W. (1970). Sex typing and socialization. In P. H. Mussen (Ed.), Carmichael's manual of child psychology (Vol. 2, 3rd ed.) (pp. 3-72). New York: Wiley.

Mischel, w. (1973). Toward a cognitive social learning reconceptualization of personality. Psychological Review, 80, 252-283.

Nilson, A. P. (1977). Alternatives to sexist practices in the classroom. Young Children, 32(5), 53-58.

O'Brien, M. , \& Huston, A. C. (1985). Development of sextyped play behavior in toddlers. Developmental Psychology, 21(5), 866-871.

Peretti, P. O., \& Sydney, T. M. (1984). Parental toy choice stereotyping and its effects on child toy preferences and sex-role typing. Social Behavior and Personality, 12 , 213-216.

Perloff, R. M. (1977). Some antecedents of children's sexrole stereotypes. Psychological Reports, 40, 463-466.

Pomerleau, A., Bolduc, D., Malcuit, G., \& Cossette, L. (1990). Pink or blue: Environmental gender stereotypes in the first two years of life. Sex Roles, 22(5/6), 359-367. 
Reid, P. T., \& Stephens, D. S. (1985). The roots of future occupations in childhood. Youth \& Society, 16(3), 267288 .

Rheingold, H. L., \& Cook, K. V. (1975). The contents of boys' and girls' rooms as an index of parents'

behavior. Child Development, 46, 459-463.

Roopnarine, J. L., \& Mounts, N. S. (1987). Current theoretical issues in sex roles and sex typing. In D. B. Carter (Ed.), current Conceptions of Sex Roles and Sex Typing (pp. 7-31). New York: Praeger.

Ross, D. M., \& Ross, S. A. (1972). Resistance by preschool boys to sex-inappropriate behavior. Journal of Educational Psychology, 63(4), 342-346.

Schau, C. G., Kahn, L., Diepold, J. H., \& Cherry, F. (1980). The relationships of parental expectations and preschool children's verbal sex typing to their sextyped toy behavior. Child Development, 51, 266-270.

Schwartz, L. A. \& Markham, W. T. (1985). Sex stereotyping in children's toy advertisements. Sex Roles, $\underline{12}(1 / 2), 157-$ 170 .

Serbin, L. A., \& Connor, J. M. (1979). Sex-typing of children's play preferences and patterns of cognitive performance. The Journal of Genetic Psychology, 134, 315-316.

Serbin, L. A., Zelkowitz, P., Doyle, A., Gold, D., \& wheaton, B. (1990). The socialization of sexdifferentiated skills and academic performance: A mediational model. Sex Roles, 23(11/12), 613-628.

Shell, R., \& Eisenberg, N. (1990). The role of peers' gender in children's naturally occurring interest in toys. International Journal of Behavioral Development, 13(3), 373-388.

Sprafkin, C., Serbin. L. A., Denier, C., Connor, J. M. (1983). Sex-differentiated play: Cognitive consequences and early interventions. In M. B. Liss (Ed.), Social and Cognitive Skills (pp. 167-192). New York: Academic Press.

Stern, D. N. (1990), Diary of a baby. Basic Books. 
Strangor, C., \& Ruble, D. N. (1987). Development of role knowledge and gender constancy. In L. S. Liben \& M. L. Signorella (Eds.), Children's Gender Schemata (pp. 5$22)$. San Francisco: Jossey-Bass.

Sylva, K. (1984). A hard-headed look at the fruits of play. Early Childhood Development and Care, 15(2-3), 171-183.

Tracy, D. M. (1990). Toy-playing behavior, sex-role orientation, spacial ability, and science achievement. Journal of Research in Science Teaching, 27(7), 637649 .

Weinraub, M., Clemens, L. P., Sockloff, A., Ethridge, T., Gracely, E., \& Myers, B. (1984). The development of sex role stereotypes in the third year: Relationships to gender labeling, gender identity, sex-typed toy preference, and family characteristics. Child Development, 55, 1493-1503.

Williams, P. A., Haertel, E. H., Haertel, G. D., \& Walberg, H. J. (1982). The impact of leisure-time television on school learning: A research synthesis. American Educational Research Journal, 19(1), 19-50.

Windle, M. S. (1987). Measurement issues in sex roles and sex typing. In D. B. Carter (Ed.), current Conceptions of Sex Roles and Sex Typing (pp. 34-45). New York: Praeger.

Wolfgang, C. H. (1983). A study of play as a predictor of social-emotional development. Early Child Development and Care, 13(1), 33-54.

Wynn, R. L., \& Fletcher, C. (1987). Sex role development and early educational experiences. In D. B. Carter (Ed.), Current Conceptions of Sex Roles and Sex Typing (pp. 50-77). New York: Praeger.

Zebrowitz McArthur, L., \& Eisen, S. V. (1976). Television and sex-role stereotyping. Journal of Applied Social Psychology, $\underline{6}(4), 329-351$. 


\section{APPENDIX A}

QUESTIONNAIRE 
QUESTIONNAIRE

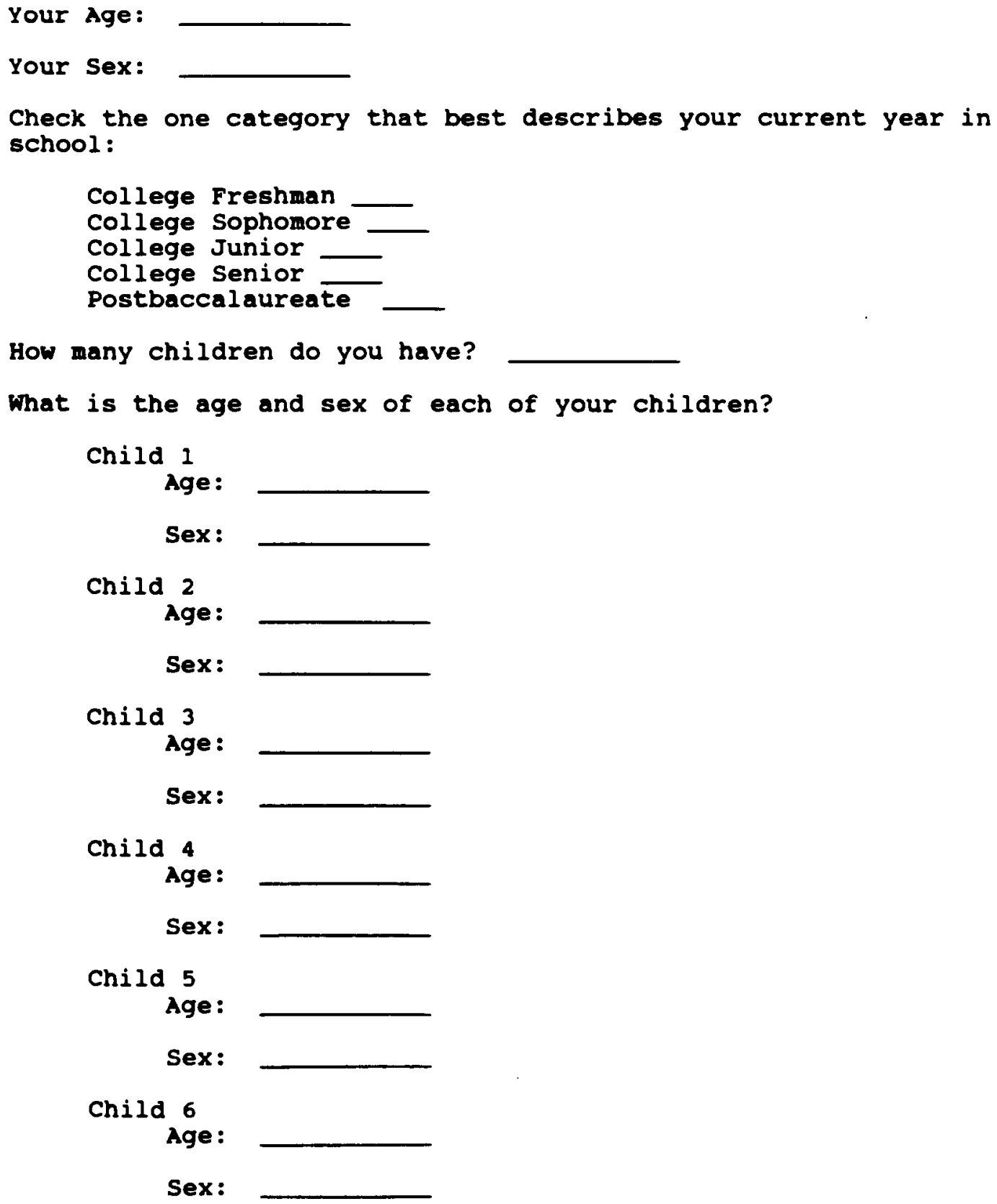

Check the one category that best describes your current year in school:

College Freshman College Sophomore

College Junior College Senior Postbaccalaureate

How many children do you have?

What is the age and sex of each of your children?

Child I

Age:

Sex :

Child 2

Age:

Sex :

Child 3

Age:

Sex:

Child 4

Age:

Sex:

Child 5

Age:

Sex:

Child 6

Age:

Sex : 
Using any criteria you choose, please rate the following pairs of toys according to similarity.

VERY

VERY

SIMILAR

DISSIMIIAR

$\begin{array}{rlllllllll}\text { painting set : carpenter set } & 1 & 2 & 3 & 4 & 5 & 6 & 7 & 8 & 9 \\ \text { baseball : jump rope } & 1 & 2 & 3 & 4 & 5 & 6 & 7 & 8 & 9 \\ \text { play-doh : puzzle } & 1 & 2 & 3 & 4 & 5 & 6 & 7 & 8 & 9 \\ \text { doll : painting set } & 1 & 2 & 3 & 4 & 5 & 6 & 7 & 8 & 9 \\ \text { jump rope : play-doh } & 1 & 2 & 3 & 4 & 5 & 6 & 7 & 8 & 9 \\ \text { sewing kit : truck } & 1 & 2 & 3 & 4 & 5 & 6 & 7 & 8 & 9 \\ \text { carpenter set : doll } & 1 & 2 & 3 & 4 & 5 & 6 & 7 & 8 & 9 \\ \text { blocks : baseball } & 1 & 2 & 3 & 4 & 5 & 6 & 7 & 8 & 9 \\ \text { painting set : puzzle } & 1 & 2 & 3 & 4 & 5 & 6 & 7 & 8 & 9 \\ \text { truck : doll } & 1 & 2 & 3 & 4 & 5 & 6 & 7 & 8 & 9 \\ \text { jump rope : blocks } & 1 & 2 & 3 & 4 & 5 & 6 & 7 & 8 & 9 \\ \text { baseball : sewing kit } & 1 & 2 & 3 & 4 & 5 & 6 & 7 & 8 & 9 \\ \text { play-doh : truck } & 1 & 2 & 3 & 4 & 5 & 6 & 7 & 8 & 9 \\ \text { blocks : painting set } & 1 & 2 & 3 & 4 & 5 & 6 & 7 & 8 & 9 \\ \text { play-doh : carpenter set } & 1 & 2 & 3 & 4 & 5 & 6 & 7 & 8 & 9 \\ \text { doll : puzzle } & 1 & 2 & 3 & 4 & 5 & 6 & 7 & 8 & 9 \\ \text { truck : jump rope } & 1 & 2 & 3 & 4 & 5 & 6 & 7 & 8 & 9 \\ \text { baseball : painting set } & 1 & 2 & 3 & 4 & 5 & 6 & 7 & 8 & 9 \\ \text { carpenter set : puzzle } & 1 & 2 & 3 & 4 & 5 & 6 & 7 & 8 & 9 \\ \text { sewing kit : play-doh } & 1 & 2 & 3 & 4 & 5 & 6 & 7 & 8 & 9 \\ \text { sump rope : painting set } & 1 & 2 & 3 & 4 & 5 & 6 & 7 & 8 & 9 \\ \text { blocks : doll } & 1 & 2 & 3 & 4 & 5 & 6 & 7 & 8 & 9 \\ \text { ang kit : jump rope } & 1 & 2 & 3 & 4 & 5 & 6 & 7 & 8 & 9\end{array}$


truck : baseball

painting set : play-doh

jump rope : doll

blocks : carpenter set

truck : blocks

puzzle : baseball

carpenter set : truck

doll : sewing kit

play-doh : doll

sewing set : carpenter set

truck : puzzle

baseball : carpenter set

sewing kit : blocks

jump rope : puzzle

painting set : truck

blocks : play-doh

play-doh : puzzle

carpenter set : jump rope

puzzle : sewing kit

baseball : doll

blocks : puzzle

sewing kit : painting set

play-doh : baseball

painting set : puzzle

sewing kit : truck

\begin{tabular}{|c|c|c|c|c|c|c|c|}
\hline 1 & 2 & 3 & 4 & 5 & 6 & 7 & 8 \\
\hline 1 & 2 & 3 & 4 & 5 & 6 & 7 & 8 \\
\hline 1 & 2 & 3 & 4 & 5 & 6 & 7 & 8 \\
\hline 1 & 2 & 3 & 4 & 5 & 6 & 7 & 8 \\
\hline 1 & 2 & 3 & 4 & 5 & 6 & 7 & 8 \\
\hline 1 & 2 & 3 & 4 & 5 & 6 & 7 & 8 \\
\hline 1 & 2 & 3 & 4 & 5 & 6 & 7 & 8 \\
\hline 1 & 2 & 3 & 4 & 5 & 6 & 7 & 8 \\
\hline 1 & 2 & 3 & 4 & 5 & 6 & 7 & 8 \\
\hline 1 & 2 & 3 & 4 & 5 & 6 & 7 & 8 \\
\hline 1 & 2 & 3 & 4 & 5 & 6 & 7 & 8 \\
\hline 1 & 2 & 3 & 4 & 5 & 6 & 7 & 8 \\
\hline 1 & 2 & 3 & 4 & 5 & 6 & 7 & 8 \\
\hline 1 & 2 & 3 & 4 & 5 & 6 & 7 & 8 \\
\hline 1 & 2 & 3 & 4 & 5 & 6 & 7 & 8 \\
\hline 1 & 2 & 3 & 4 & 5 & 6 & 7 & 8 \\
\hline 1 & 2 & 3 & 4 & 5 & 6 & 7 & 8 \\
\hline 1 & 2 & 3 & 4 & 5 & 6 & 7 & 8 \\
\hline 1 & 2 & 3 & 4 & 5 & 6 & 7 & 8 \\
\hline 1 & 2 & 3 & 4 & 5 & 6 & 7 & 8 \\
\hline 1 & 2 & 3 & 4 & 5 & 6 & 7 & 8 \\
\hline 1 & 2 & 3 & 4 & 5 & 6 & 7 & 8 \\
\hline 1 & 2 & 3 & 4 & 5 & 6 & 7 & 8 \\
\hline 1 & 2 & 3 & 4 & 5 & 6 & 7 & 8 \\
\hline 1 & 2 & 3 & 4 & 5 & 6 & 7 & 8 \\
\hline
\end{tabular}


Rate the following dimensions for each toy listed below. In all the ratings below, please give your opinion, not what other people think. Please be aware that the toys are not in the same order for each dimension.

In terms of its texture, this toys appears to me to be:

\begin{tabular}{lccccccccr} 
& SOFT & \multicolumn{3}{c}{$\begin{array}{c}\text { SOMEWHAT } \\
\text { SOFT }\end{array}$} & \multicolumn{3}{c}{$\begin{array}{c}\text { SOMEWHAT } \\
\text { HARD }\end{array}$} & & HARD \\
puzzle & 1 & 2 & 3 & 4 & 5 & 6 & 7 & 8 & 9 \\
baseball & 1 & 2 & 3 & 4 & 5 & 6 & 7 & 8 & 9 \\
sewing kit & 1 & 2 & 3 & 4 & 5 & 6 & 7 & 8 & 9 \\
painting set & 1 & 2 & 3 & 4 & 5 & 6 & 7 & 8 & 9 \\
truck & 1 & 2 & 3 & 4 & 5 & 6 & 7 & 8 & 9 \\
play-don & 1 & 2 & 3 & 4 & 5 & 6 & 7 & 8 & 9 \\
carpenter set & 1 & 2 & 3 & 4 & 5 & 6 & 7 & 8 & 9 \\
jump rope & 1 & 2 & 3 & 4 & 5 & 6 & 7 & 8 & 9 \\
blocks & 1 & 2 & 3 & 4 & 5 & 6 & 7 & 8 & 9 \\
doll & 1 & 2 & 3 & 4 & 5 & 6 & 7 & 8 & 9
\end{tabular}

In terms of its color, this toys appears to me to be:

$$
\text { SONEWHAT SOMEWHAT }
$$

baseball

painting set

play-doh

PALE

$\begin{array}{lllllllll}1 & 2 & 3 & 4 & 5 & 6 & 7 & 8 & 9\end{array}$

jump rope

doll

blocks

carpenter set

$\begin{array}{lllllllll}1 & 2 & 3 & 4 & 5 & 6 & 7 & 8 & 9\end{array}$

$\begin{array}{lllllllll}1 & 2 & 3 & 4 & 5 & 6 & 7 & 8 & 9\end{array}$

truck

sewing kit

puzzle

$$
\begin{array}{lllllllll}
1 & 2 & 3 & 4 & 5 & 6 & 7 & 8 & 9 \\
1 & 2 & 3 & 4 & 5 & 6 & 7 & 8 & 9
\end{array}
$$

$\begin{array}{lllllllll}1 & 2 & 3 & 4 & 5 & 6 & 7 & 8 & 9\end{array}$

$\begin{array}{lllllllll}1 & 2 & 3 & 4 & 5 & 6 & 7 & 8 & 9\end{array}$

$\begin{array}{lllllllll}1 & 2 & 3 & 4 & 5 & 6 & 7 & 8 & 9\end{array}$

$\begin{array}{lllllllll}1 & 2 & 3 & 4 & 5 & 6 & 7 & 8 & 9\end{array}$

$\begin{array}{lllllllll}1 & 2 & 3 & 4 & 5 & 6 & 7 & 8 & 9\end{array}$ 
In terms of its shape, this toys appears to me to have:

\section{ROUNDED}

sewing kit

play-doh

blocks

basebal1

carpenter set

doll

puzzle

painting set

jump rope

truck

$\begin{array}{lllllllll}1 & 2 & 3 & 4 & 5 & 6 & 7 & 8 & 9 \\ 1 & 2 & 3 & 4 & 5 & 6 & 7 & 8 & 9 \\ 1 & 2 & 3 & 4 & 5 & 6 & 7 & 8 & 9 \\ 1 & 2 & 3 & 4 & 5 & 6 & 7 & 8 & 9 \\ 1 & 2 & 3 & 4 & 5 & 6 & 7 & 8 & 9 \\ 1 & 2 & 3 & 4 & 5 & 6 & 7 & 8 & 9 \\ 1 & 2 & 3 & 4 & 5 & 6 & 7 & 8 & 9 \\ 1 & 2 & 3 & 4 & 5 & 6 & 7 & 8 & 9 \\ 1 & 2 & 3 & 4 & 5 & 6 & 7 & 8 & 9 \\ 1 & 2 & 3 & 4 & 5 & 6 & 7 & 8 & 9\end{array}$

Playing with this toys involves:

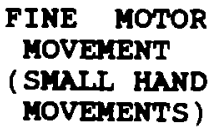

GROSS MOTOR

MOVEMENT

(LARGE BODY

MOVEMENTS )

doll

puzzle

baseba 11

blocks

painting set

jump rope

truck

carpenter set

sewing $k i t$

play-doh

$\begin{array}{lllllllll}1 & 2 & 3 & 4 & 5 & 6 & 7 & 8 & 9 \\ 1 & 2 & 3 & 4 & 5 & 6 & 7 & 8 & 9 \\ 1 & 2 & 3 & 4 & 5 & 6 & 7 & 8 & 9 \\ 1 & 2 & 3 & 4 & 5 & 6 & 7 & 8 & 9 \\ 1 & 2 & 3 & 4 & 5 & 6 & 7 & 8 & 9 \\ 1 & 2 & 3 & 4 & 5 & 6 & 7 & 8 & 9 \\ 1 & 2 & 3 & 4 & 5 & 6 & 7 & 8 & 9 \\ 1 & 2 & 3 & 4 & 5 & 6 & 7 & 8 & 9 \\ 1 & 2 & 3 & 4 & 5 & 6 & 7 & 8 & 9 \\ 1 & 2 & 3 & 4 & 5 & 6 & 7 & 8 & 9\end{array}$


Children play with this toy in:

\begin{tabular}{|c|c|c|c|c|c|c|c|c|c|}
\hline \multirow[b]{2}{*}{ play-doh } & \multicolumn{2}{|c|}{$\begin{array}{l}\text { SMALL } \\
\text { GROUPS }\end{array}$} & \multicolumn{5}{|c|}{$\begin{array}{l}\text { MANY IN } \\
\text { A GROUP }\end{array}$} & & \multirow{2}{*}{$\begin{array}{l}\text { LARGE } \\
\text { GROUPS } \\
9\end{array}$} \\
\hline & 1 & 2 & 3 & 4 & 5 & 6 & 7 & 8 & \\
\hline carpenter set & 1 & 2 & 3 & 4 & 5 & 6 & 7 & 8 & 9 \\
\hline jump rope & 1 & 2 & 3 & 4 & 5 & 6 & 7 & 8 & 9 \\
\hline blocks & 1 & 2 & 3 & 4 & 5 & 6 & 7 & 8 & 9 \\
\hline doll & 1 & 2 & 3 & 4 & 5 & 6 & 7 & B & 9 \\
\hline truck & 1 & 2 & 3 & 4 & 5 & 6 & 7 & B & 9 \\
\hline baseball & 1 & 2 & 3 & 4 & 5 & 6 & 7 & B & 9 \\
\hline painting set & 1 & 2 & 3 & 4 & 5 & 6 & 7 & 8 & 9 \\
\hline puzzle & 1 & 2 & 3 & 4 & 5 & 6 & 7 & 8 & 9 \\
\hline sewing kit & 1 & 2 & 3 & 4 & 5 & 6 & 7 & 8 & 9 \\
\hline
\end{tabular}

This toy is suppose to be for:

$\begin{array}{llll}\text { ONLY } & \text { MOSTLY } & \text { MOSTLY } & \text { ONLY } \\ \text { GIRLS } & \text { GIRLS } & \text { BOYS } & \text { BOYS }\end{array}$

\begin{tabular}{|c|c|c|c|c|c|c|c|c|c|}
\hline painting set & 1 & 2 & 3 & 4 & 5 & 6 & 7 & 8 & 9 \\
\hline carpenter set & 1 & 2 & 3 & 4 & 5 & 6 & 7 & 8 & 9 \\
\hline truck & 1 & 2 & 3 & 4 & 5 & 6 & 7 & 8 & 9 \\
\hline sewing kit & 1 & 2 & 3 & 4 & 5 & 6 & 7 & 8 & 9 \\
\hline puzzle & 1 & 2 & 3 & 4 & 5 & 6 & 7 & 8 & 9 \\
\hline juwp rope & 1 & 2 & 3 & 4 & 5 & 6 & 7 & 8 & 9 \\
\hline blocks & 1 & 2 & 3 & 4 & 5 & 6 & 7 & 8 & 9 \\
\hline doll & 1 & 2 & 3 & 4 & 5 & 6 & 7 & 8 & 9 \\
\hline play-don & 1 & 2 & 3 & 4 & 5 & 6 & 7 & 8 & 9 \\
\hline baseball & 1 & 2 & 3 & 4 & 5 & 6 & 7 & 8 & 9 \\
\hline
\end{tabular}


This toys appears to me to have:

FLAT SURFACE

HEIGHT-WIDTH-DEPTH

(TWO-DIMENSTONAL)

( THREE-DIMENSIONAI)

truck

doll

blocks

jump rope

$\begin{array}{lllllllll}1 & 2 & 3 & 4 & 5 & 6 & 7 & 8 & 9 \\ 1 & 2 & 3 & 4 & 5 & 6 & 7 & 8 & 9 \\ 1 & 2 & 3 & 4 & 5 & 6 & 7 & 8 & 9 \\ 1 & 2 & 3 & 4 & 5 & 6 & 7 & 8 & 9 \\ 1 & 2 & 3 & 4 & 5 & 6 & 7 & 8 & 9 \\ 1 & 2 & 3 & 4 & 5 & 6 & 7 & 8 & 9 \\ 1 & 2 & 3 & 4 & 5 & 6 & 7 & 8 & 9 \\ 1 & 2 & 3 & 4 & 5 & 6 & 7 & 8 & 9 \\ 1 & 2 & 3 & 4 & 5 & 6 & 7 & 8 & 9 \\ 1 & 2 & 3 & 4 & 5 & 6 & 7 & 8 & 9\end{array}$

carpenter set

12

painting set

sewing kit

puzzle

play-doh

9

9

9

baseball

$t$

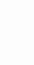


We are interested in how familiar you are with the toys you've fust rated. For each toy listed below, would you please indicate, by marking the appropriate colum, whether you have in your home, or have had in your home at one tine, (a) exactly this toy, (b) a similar toy but different version (1.e., different color, different manufacturer, different shape, etc.), or (c) neither of the above (i.e., you don't have this or a similar toy in your home, or you have never had this or a similar toy in your home).

$\begin{array}{ll}\text { Exactly } & \text { A Similar Toy But } \\ \text { This Toy } & \text { Tifferent or Aersion Similar }\end{array}$

Puzzle
baseball
Sewing kit
Painting set
Truck
Play-Doh
Carpenter set
Jump rope
Blocks
Doll

I Do Not Have/Have Never Hed This Toy In Hy Hone
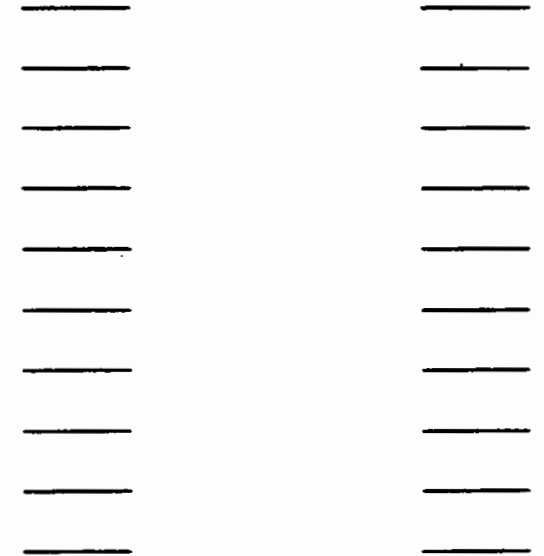
BELON IS A LIST OF TERMS UNIUERSITY STUDENTS TAKING PART IN RESEARCH HAUE USED TO DESCRIBE THEMSELUES. READ THE TERTS, AND WRITE THE APPROPRIATE NUMBER BESIDE EACH, USING A 7-POINT SCALE TO RATE YOURSELF AS FOLLOWS:

NOT AT ALL DESCRIPTIVE OF ME

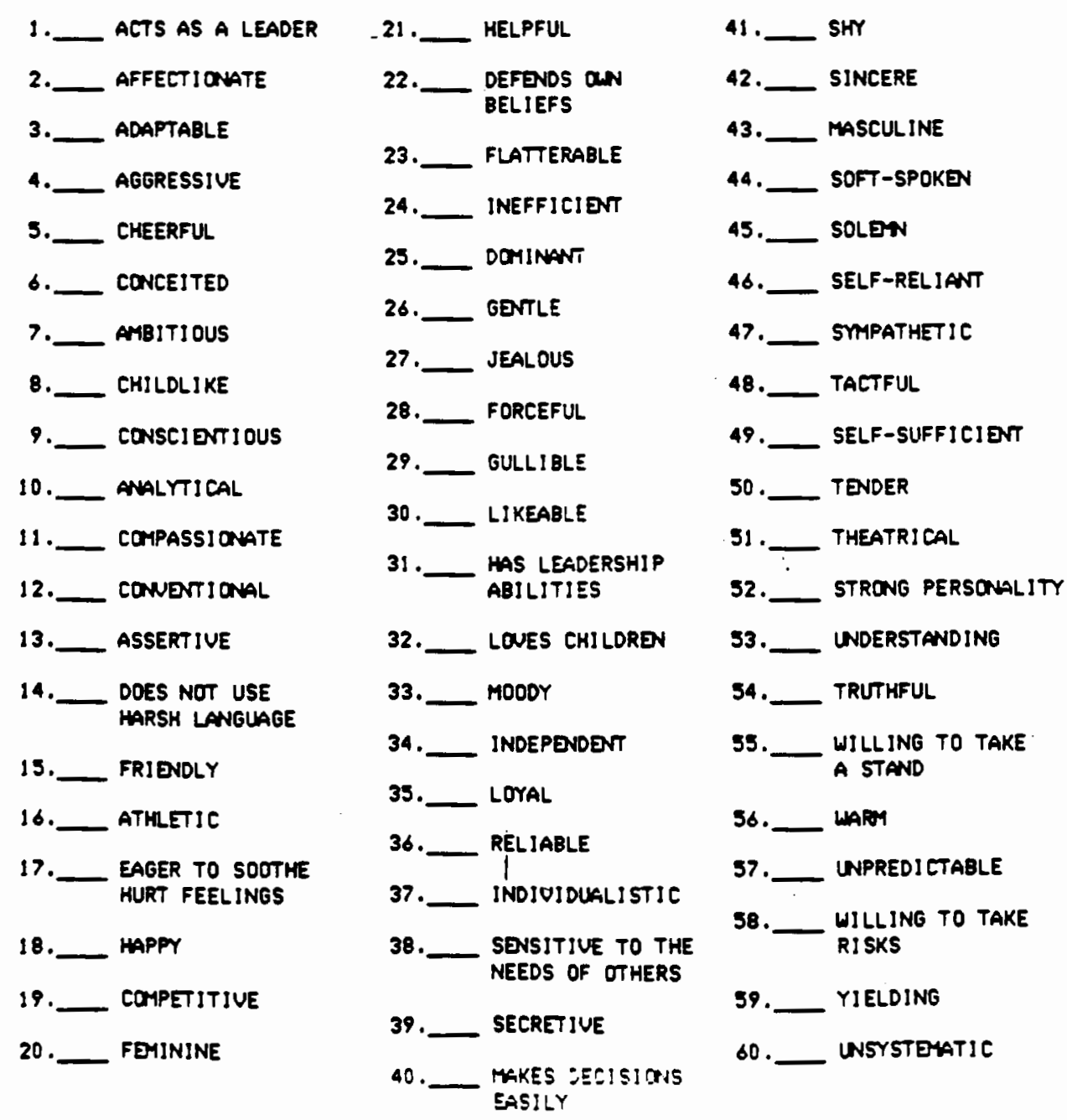


APPENDIX B

INFORMED CONSENT 


\section{Informed consent}

I, , hereby agree to serve as a

subject in the research project examining the dimensions of toys, conducted by Shelly Jackson.

I understand that the study involves filling out a short questionnaire asking my age, gender, education, as well as the number, age, and gender of my children. Following this I will rate ten toys, two at a time, on their similarity to each other. I will then rate the ten toys on eight dimensions.

I understand that the possible risk to me associated with this study is the demand it places on my time. I am aware that the ratings will take about one-half-hour of my time.

It has been explained to me that the purpose of this study is to learn the important dimensions of toys.

I may not receive any direct benefit from participation in this study, but my participation may help to increase knowledge which may benefit others in the future.

Shelly Jackson has offered to answer any questions I may have about the study and what is expected of me in the study. I have been assured that all information I give will be kept confidential and that the identity of all subjects will remain anonymous.

I understand that I am free to withdraw from participation in this study at any time without jeopardizing my course grade or my relationship with Portland State University.

I have read and understand the foregoing information and agree to participate in this study.

Date Signature

If you experience problems that are the result of your participation in this study, please contact the chair of the Human subjects Research Review Committee, Office of Grants and Contracts, 345 Cramer Hall, Portland State University, (503)725-3417. 